Research Article

\title{
Wideband and High-Efficiency SIW Cavity-Backed Magneto-Electric Dipole Antenna Array
}

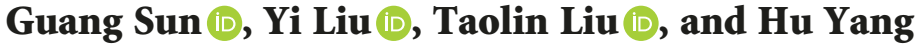 \\ College of Electronic Science and Technology, National University of Defense Technology, 410073 Changsha, China \\ Correspondence should be addressed to Guang Sun; sunguang17@nudt.edu.cn
}

Received 21 July 2019; Revised 27 September 2019; Accepted 16 October 2019; Published 16 November 2019

Academic Editor: Shah Nawaz Burokur

Copyright ( $\odot 2019$ Guang Sun et al. This is an open access article distributed under the Creative Commons Attribution License, which permits unrestricted use, distribution, and reproduction in any medium, provided the original work is properly cited.

In this paper, a compact, wideband, and high-efficiency substrate integrated waveguide (SIW) feeding cavity-backed aperturecoupled magneto-electric (ME) dipole antenna element and its array are proposed. Firstly, an SIW cavity-backed and a modified bowtie dipole are designed for the antenna element which makes it possess a high gain and wide impedance bandwidth. The antenna element covers an impedance bandwidth of $66.3 \%$ from 10.7 to $21.3 \mathrm{GHz}$ with a peak gain of $10.3 \mathrm{dBi}$. Secondly, a $4 \times 4$ array is designed using the proposed antenna element. And a full-corporate substrate integrated waveguide feeding network is introduced to excite the array elements for the antenna application with wide bandwidth and high efficiency. For validation, a prototype of $4 \times 4$ array is fabricated by standard printed circuit board (PCB) facilities and further measured. The measured $-10 \mathrm{~dB}$ impedance bandwidth of the proposed $4 \times 4$ antenna array is $30 \%(12.75-17.25 \mathrm{GHz})$ with its gain being $18.2-20.9 \mathrm{dBi}$ within the entire band. The measured maximum aperture efficiency of the antenna array is $94 \%$ at $14.92 \mathrm{GHz}$. Notably, the measured results agree well with simulations, and it shows great advantages over other similar antennas on efficiency and bandwidth.

\section{Introduction}

In recent years, radar systems have received widespread attention for their ability to detect, identify, and monitor a variety of targets. Many of its most recent advances include a reduction in overall weight and an increase in performance rate [1]. Particularly, due to the high propagation loss and the limited transmit power, the development of high-gain planar antennas with high efficiency and wide bandwidth is promising for vital applications in radar systems at Ku-band. However, most of the antenna arrays usually suffer from narrow impedance bandwidth or low efficiency; how to simultaneously achieve a wider impedance bandwidth and higher efficiency is a key issue that needs to be solved.

The antenna arrays always include a number of antenna elements, and the performance of the antenna element is especially important for antenna arrays. Therefore, a great interest has been addressed to the design of wideband and high-gain antenna element. Microstrip patch or slot antenna has been widely studied and applied in many radar or communication systems due to many advantages like its light weight, low profile, low cost, and ease of integration [2]. However, it usually suffers from narrow impedance bandwidth or unstable radiation patterns within the operating bandwidth. Although various techniques have been successfully developed to enhance bandwidth, including the use of stacked patches, coupling slots, or shorting vias [3-5], the radiation characteristics of the antenna vary significantly within the operating bandwidth. A wideband unidirectional antenna, which is commonly known as magneto-electric (ME) dipole antenna, was proposed in [6]. The antenna using the theory of complementary antenna which has advantages of wide bandwidth and stable unidirectional radiation patterns with low cross-polarization and low back radiation. What is more, several improved designs for enhancing its impedance bandwidth and gain have been proposed [7-13]; the methods mainly include loading parasitic patches, increasing open slots, or using EBG style [7-10]. Although these antennas can achieve a wider bandwidth, their structures are large and complicated, and the metal manufacturing process 
increases the difficulty and cost. As a mature technology, the printed circuit board (PCB) process is widely used in microstrip-based and SIW-based antennas, due to its low cost and simple processing [11-14]. In [12], a new wideband ME dipole antenna, realized by using standard PCB technique, is proposed for $60-\mathrm{GHz}$ millimeter-wave applications; the antenna has a simple structure and is convenient in design. However, the antenna is fed by the probe, which is not convenient to the connection of the feeding network if it is used as an array element. In [13], a wideband cavity-backed ME dipole antenna is excited by a stripline aperture-coupled feeding structure to reach wide bandwidth and high gain. However, the size of the antenna is large, and the metallic cavity-backed increases its weight and the cost of fabrication. Therefore, it is very necessary to design a compact and wideband antenna element with high gain.

Significant progresses have been made on the bandwidth enhancement and gain improvement for the ME dipole antennas with PCB technique. However, the antenna efficiency is also affected by the loss of the feeding network. Therefore, besides the antenna element, the feeding network is also an important factor affecting the bandwidth and efficiency of the antenna array. Due to the advantages of low profile and easy integration with planar circuits, microstrip planar transmission lines are widely used in feeding networks for antenna arrays. However, they have high radiation loss and dielectric loss [15], so they are not suitable as a feeding network at high frequencies. The metallic waveguides, including conventional rectangular waveguides, hollow waveguides, and gap waveguides, due to the advantage of low loss at the high-frequency bands, are promising for the high-efficiency antenna arrays [16-20]. However, the metal waveguide is bulky, heavy, and expensive to manufacture, which is not suitable for mass production. In [21], a planar antenna array using printed ridge gap waveguide technology was proposed, which is selfpackaged with low loss. However, this array has high design complexity and requires high production accuracy especially at high frequencies. SIW inherits the merits from both microstrip lines and metal waveguides and has the advantages of low transmission loss, low fabrication costs, ease of integration, and so on. Therefore, it has been widely used in antenna arrays [22-33]. Series feeding networks based on SIW have lower transmission loss and excellent radiation performance. However, large antenna arrays with series feeding networks suffer from narrow bandwidth [23-25]. Therefore, SIW full-corporate feeding networks, due to their ability of low loss and wide bandwidth, have been widely used in planar patch or slot antenna arrays in recent years [26-33]. In [33], a wideband ME dipole antenna element and its array is proposed with good unidirectional radiation performance. However, the research found that as the impedance bandwidth expands, the radiation pattern of the element will be asymmetry. Therefore, a wideband highefficiency cavity-backed ME dipole antenna arrays using PCB technique with full-corporate SIW feeding networks is seldom proposed.

In this paper, a compact, wideband, and high-efficiency SIW cavity-backed aperture-coupled magneto-electric dipole antenna element and its $4 \times 4$ antenna array is designed based on the full-corporate SIW feeding networks. In order to increase the gain of the antenna element, a SIW cavity-backed is introduced. And two open gaps are etched onto the bowtie dipole patch to extend the impedance bandwidth of the antenna. To achieve better impedance matching, a modified bowtie dipole is designed. A $2 \times 2$ subarray is formed by adopting a four-way aperture-coupled power divider. Based on the $2 \times 2$ subarray and full-corporate SIW feeding networks, a $4 \times 4$ antenna array is designed. Finally, to further validate the capability of the proposed antenna, a $4 \times 4$ antenna array is designed, fabricated, and tested.

\section{Antenna Configuration}

ME dipole antenna comprises a magnetic dipole and an electric dipole, which is a complementary antenna. The theory of complementary antennas and their complementary patterns are described in $[6,8]$. When the electric dipole and magnetic dipole are excited simultaneously, their radiation patterns are synthesized. Due to the complementarity of their patterns, the forward radiation of the $\mathrm{ME}$ dipole is enhanced and the backward radiation is offset. Therefore, a unidirectional radiation pattern can be generated. Figure 1 shows the configuration of the proposed wideband magneto-electric dipole antenna element. The proposed antenna consists of two components: a radiating part and a feeding part, which is etched, respectively, on two F4BM substrates with a relative permittivity of $\varepsilon_{r}=2.2$. An exploded view of the proposed wideband magneto-electric dipole antenna element is illustrated in Figure $1(\mathrm{~d})$. The radiating part is the whole ME dipole antenna, which is built in substrate 1 with a thickness of $h_{1}=3 \mathrm{~mm}$. Two pairs of modified horizontal planar bowtie metallic patches are printed on the top surface of substrate 1, which together operate as the electric dipole, as shown by the red arrow in Figure 1(d). Each bowtie metallic patch is connected to the ground through three vertical metalized via-holes. The metalized via-holes with a diameter of $d_{v}=0.5 \mathrm{~mm}$ and a pitch of $d_{f}=0.8 \mathrm{~mm}$ are arranged in rows on the inside of the bowtie metallic patch as the shorted wall, as shown in Figure 1(a). A SIW cavity-backed is formed by SIW, a bottom printed metal surface and a top open rectangular slot. Two pairs of modified planar bowtie metallic patches are surrounded by a SIW cavity-backed to obtain a high gain and good unidirectional radiation characteristics. The gap between the two pairs of modified planar bowtie patches and the two gaps between the bowtie patches and the sidewalls of SIW cavity-backed are operated as the magnetic dipoles, as shown by the blue arrow in Figure 1(d). The feeding part of the proposed antenna element is the SIW aperture-coupled feeding structure, which is processed on substrate 2 with the thickness of $h_{2}=2 \mathrm{~mm}$. The top surface of substrate 2 is directly connected to the radiating part. A feeding slot with a length of $s_{l}$ and width of $s_{w}$ is etched on the top surface of substrate 2 , which is used to feed the ME dipole antenna. The details of the feeding part are shown in Figure 1(b). The dimensions of the proposed antenna are optimized with CST 


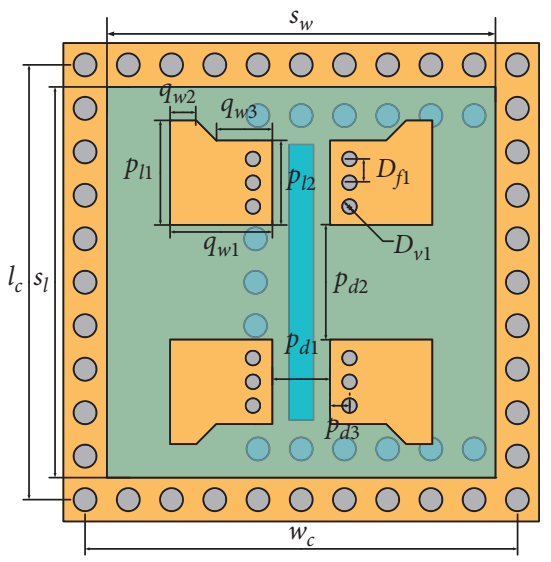

(a)

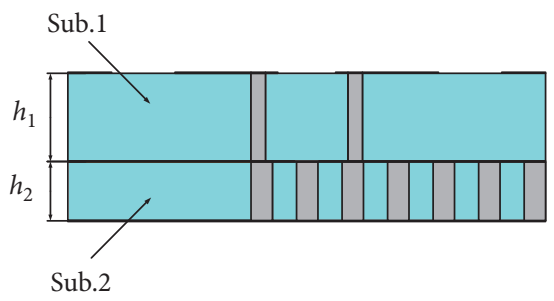

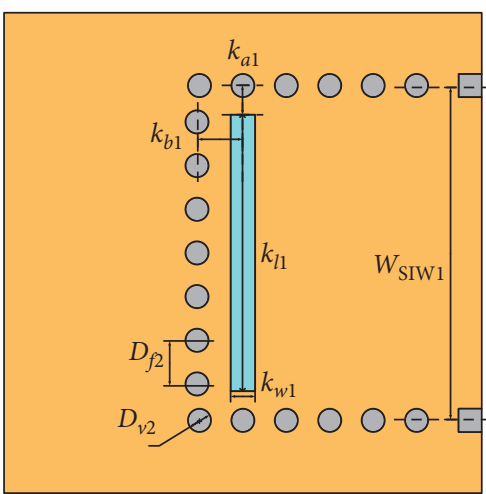

(b)

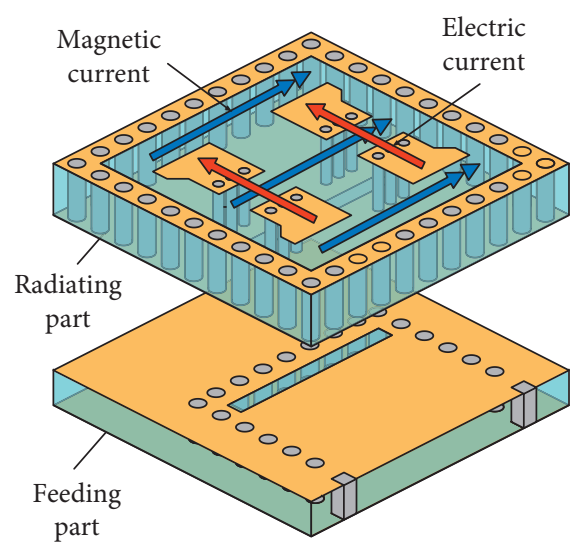

(d)

Figure 1: Configuration of the proposed antenna element. (a) Top view of radiating part. (b) Top view of feeding part. (c) Left view. (d) Exploded view.

Microwave Studio 2018. The optimized dimensions of the proposed antenna element are given in Table 1.

\section{Antenna Design and Analysis}

3.1. Design Process. Figure 2 shows the structure of the proposed antenna element and three reference antennas. The three reference antennas are shown in Figures 2(a), 2(b), and $2(\mathrm{~d})$, respectively. The corresponding reflection coefficient and gain are displayed in Figure 3 . The previously proposed antenna in [13] has a wide bandwidth and good radiation characteristics. However, the size of the antenna is larger than $2 \lambda_{0}$, and the feeding of the microstrip line increases the transmission loss, and the metalized cavitybacked increases the difficulty of processing. The antenna element in [33] can achieve a compact structure, but its structure limits the impedance bandwidth of the antenna element and also causes the asymmetrical radiation pattern at high frequencies. Thus, a PCB process is applied to reduce costs and facilitate production in the design of the proposed antenna. And an improved design of antenna element is introduced to achieve broadband and compactness of the element. In the Ant. 1, a SIW cavity-backed is introduced, instead of the metal cavity, to increase the gain and improve
TABLE 1: Dimensions of the proposed antenna element (unit: $\mathrm{mm}$ ).

\begin{tabular}{lcccccccc}
\hline Para. & $l_{c}$ & $w_{c}$ & $s_{l}$ & $s_{w}$ & $p_{l 1}$ & $p_{l 2}$ & $p_{d 1}$ & $p_{d 2}$ \\
\hline Values & 15 & 15 & 13.48 & 13.48 & 3.61 & 2.92 & 2 & 4.05 \\
Para. & $p_{d 3}$ & $q_{w 1}$ & $q_{w 2}$ & $q_{w 3}$ & $k_{a 1}$ & $k_{b 1}$ & $k_{l 1}$ & $k_{w 1}$ \\
Values & 0.83 & 3.55 & 0.91 & 1.95 & 1 & 1.16 & 9.5 & 0.85 \\
Para. & $W_{\text {siw1 }}$ & $h_{1}$ & $h_{2}$ & $D_{f 1}$ & $D_{v 1}$ & $D_{f 2}$ & $D_{v 2}$ & \\
Values & 11.5 & 3 & 2 & 0.5 & 0.8 & 0.8 & 1.5 & \\
\hline
\end{tabular}

the compactness of the proposed antenna, and a SIW aperture-coupled feeding is applied to improve the transmission efficiency and achieve a stable radiation pattern. Therefore, a modified SIW feeding cavity-backed aperturecoupled ME dipole antenna element is designed, as shown in Figure 2(a). Although Ant. 1 can achieve high gain, the impedance matching of Ant. 1 is very poor. To achieve good impedance matching, two open gaps are etched onto the dipole patch, a pair of ME dipoles is divided into two parts and moved to the sides of the SIW cavity, respectively, in Ant. 2, as shown in Figure 2(b). In Figure 3(a), it can be found that three resonance points appear in the operating band, and the impedance bandwidth is improved. To obtain a wide impedance bandwidth and better impedance matching for $\mathrm{S} 11<-15 \mathrm{~dB}$ and then to design an antenna 


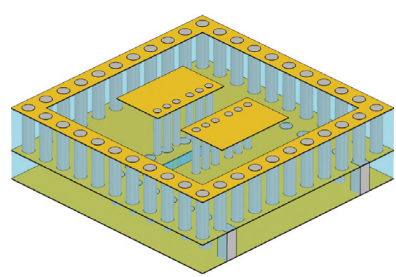

(a)

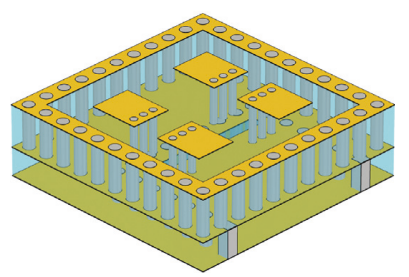

(b)

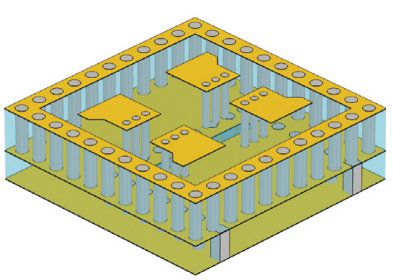

(c)

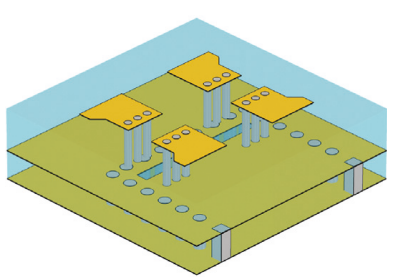

(d)

Figure 2: Configuration of the proposed different antenna element. (a) Reference ant. 1: SIW cavity-backed rectangle ME dipole antenna. (b) Reference ant. 2: modified SIW cavity-backed rectangle ME dipole antenna. (c) Proposed ant. 3: the proposed modified SIW cavitybacked bowtie ME dipole antenna. (d) Reference ant. 4: comparison of ME dipole antenna without SIW cavity-backed.

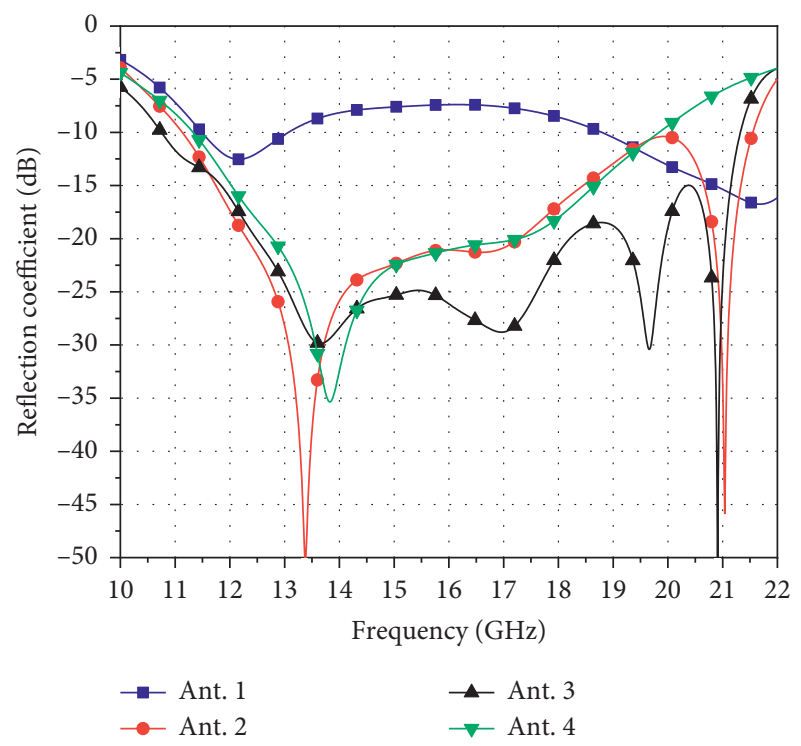

(a)

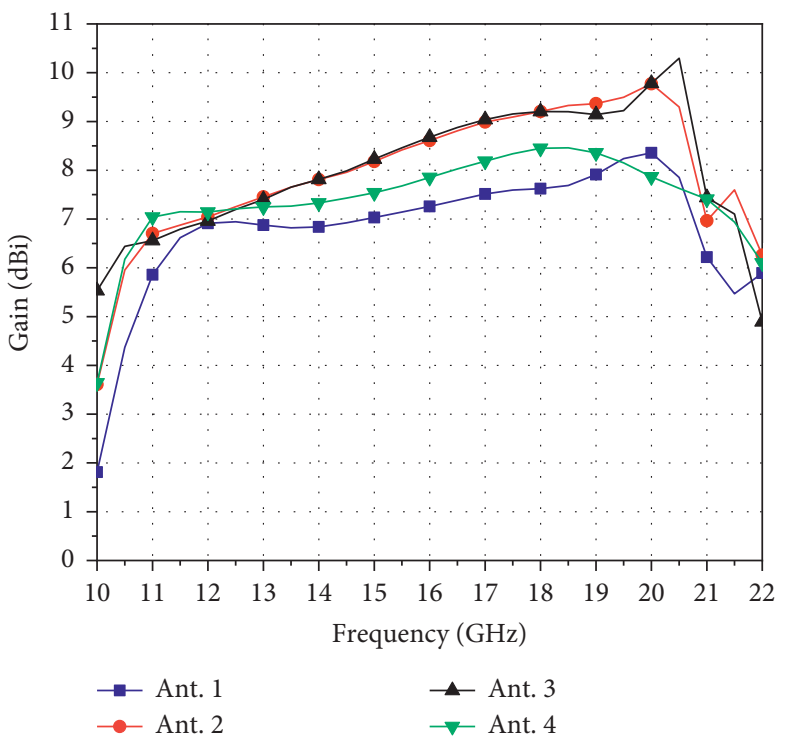

(b)

FIGURE 3: Simulated active reflection coefficient and gain in the evolution of the antennas. (a) Reflection coefficient. (b) Realized gains.

array with wider impedance bandwidth based on reference Ant. 2, the conventional rectangular dipole patch is modified to a bowtie shape in Ant. 3, as shown in Figure 2(c). In Figure 3(a), it can be found that an additional resonant mode is excited at $19.5 \mathrm{GHz}$, and the resonant depth of the antenna element is deepened within the entire bandwidth. By combining multiple resonant modes, the impedance bandwidth of Ant. 3 is further expanded, and a wider impedance bandwidth with good impedance matching is obtained.

To further understand the impact of the SIW cavity on the performance of the proposed antenna, reference Ant. 4 without the SIW cavity is designed for comparison, as shown in Figure 2(d). In Figure 3(a), it can be seen that, with the introduction of the SIW cavity-backed, two new resonance points are excited at the higher frequency band due to the coupling between the dipole patch and the edge of the SIW cavity. The impedance bandwidth of the proposed antenna is expanded at both lower and higher frequencies. Therefore, it can be concluded that both the dipoles and the SIW cavity play a significant role in the impedance matching of the element. The wide impedance matching characteristic of the proposed antenna element is the result of the dipoles and the interaction between the dipoles and the SIW cavity. And it can be seen that the gain of the proposed antenna with SIW cavity-backed is also significantly improved within the bandwidth of $12-21 \mathrm{GHz}$, shown in Figure 3(b).

3.2. Character Analysis of the Proposed Antenna. To further understand the working mechanism of the proposed cavitybacked aperture-coupled ME dipole antenna element, the simulated electric current and E-field distributions throughout the radiating aperture of the proposed Ant. 3 and the top surface of the antenna element are studied. Figures 4(a)-4(d) show the electric current and E-field distributions at time $(t)=0, T / 4, T / 2$, and $T$, respectively, where $T$ is the period. As shown in Figure 4(a), at time $t=0$, the maximum of the current distribution mainly appears on the outer edge of horizontal bowtie patches, whereas the current distribution on the vertical metalized via-holes is minimized, which is similar to the current distribution on a planar electric dipole. The direction of the electric current is mainly along the horizontal direction. Therefore, at time 


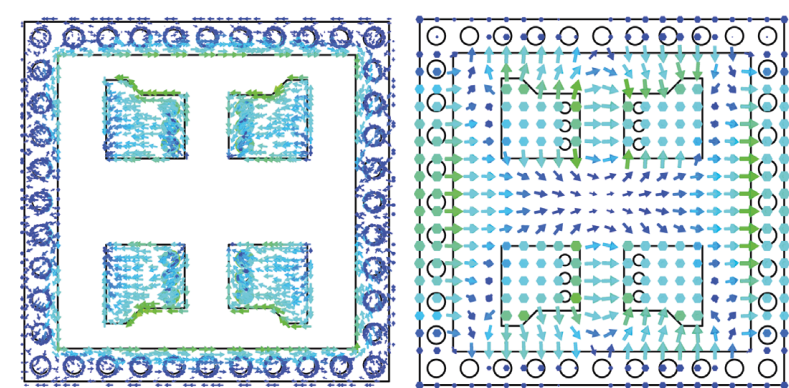

(a)

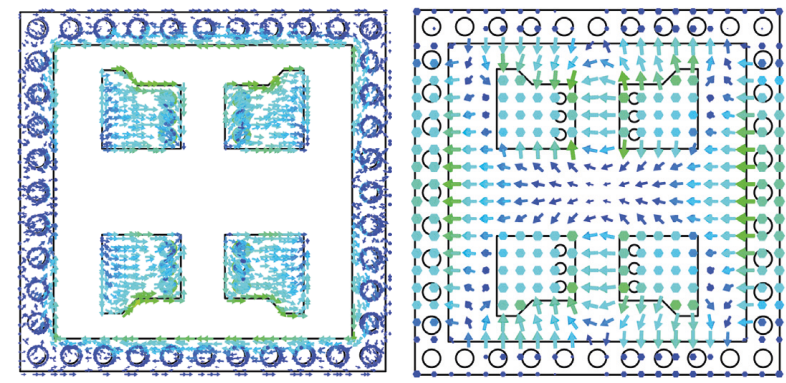

(c)

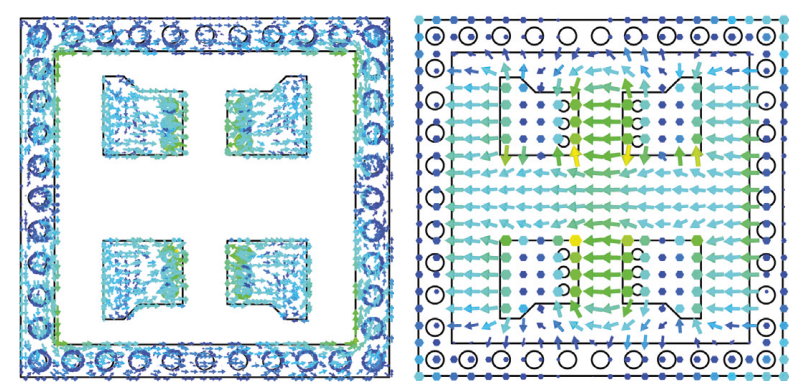

(b)

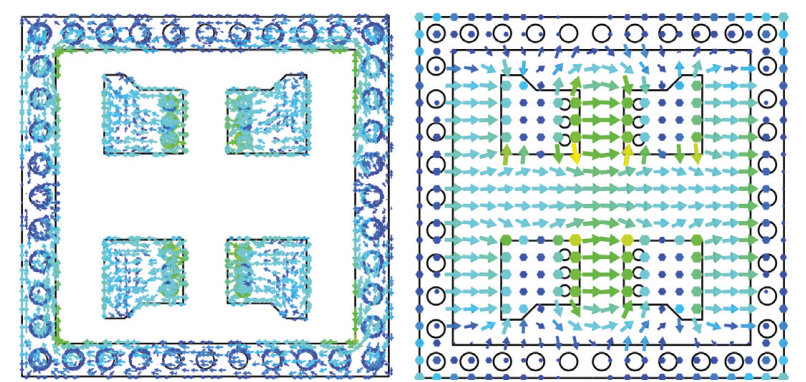

(d)

FIgURE 4: Surface current distributions and E-field distributions of the proposed antenna at (a) $t=0$, (b) $t=T / 4$, (c) $t=T / 2$, and (d) $t=3 T / 4$.

$t=0$, the electric dipole mode in the horizontal direction is motivated. In addition, the E-field of the radiating aperture is also mainly along the horizontal direction, which is the same as the direction of the electric current. At time $t=T / 4$, in Figure 4(b), the electric current on the horizontal bowtie patches is minimized, whereas the current distribution is mainly concentrated on vertical metalized via-holes. Moreover, the electric current over the left half and right half of the radiating aperture is in the opposite direction. And the directions of the electric current on the bowtie dipoles and on the sidewalls of SIW cavity are also opposite to each other. Therefore, the current loops, which radiate as three magnetic dipoles, are strongly excited. The electric field, along the horizontal direction, is mainly distributed in three radiating apertures which consist of a gap between the four bowtie patches and two gaps between the bowtie patches and the sidewalls of the SIW cavity, which is similar to the electric field distribution on magnetic dipoles. The direction of the electric field is also mainly along the horizontal direction. Therefore, at time $t=T / 4$, the equivalent magnetic dipole mode is motivated. Similarly, at time $t=T / 2$, the electric dipole is excited again with the opposite direction to the mode at time $t=0$. And at time $t=3 T / 4$, the magnetic dipole is excited again with the opposite direction to the mode at $t=T / 4$. Therefore, the complementary electric and magnetic dipoles simultaneously operate and result in a stable unidirectional radiation pattern of the proposed antenna with low back lobe and low cross-polarization.

3.3. Simulated Results of the Antenna Element. The full-wave simulated results of reflection coefficient and gain of the proposed antenna element are shown in Figure 5, which shows that the impedance bandwidth of the proposed

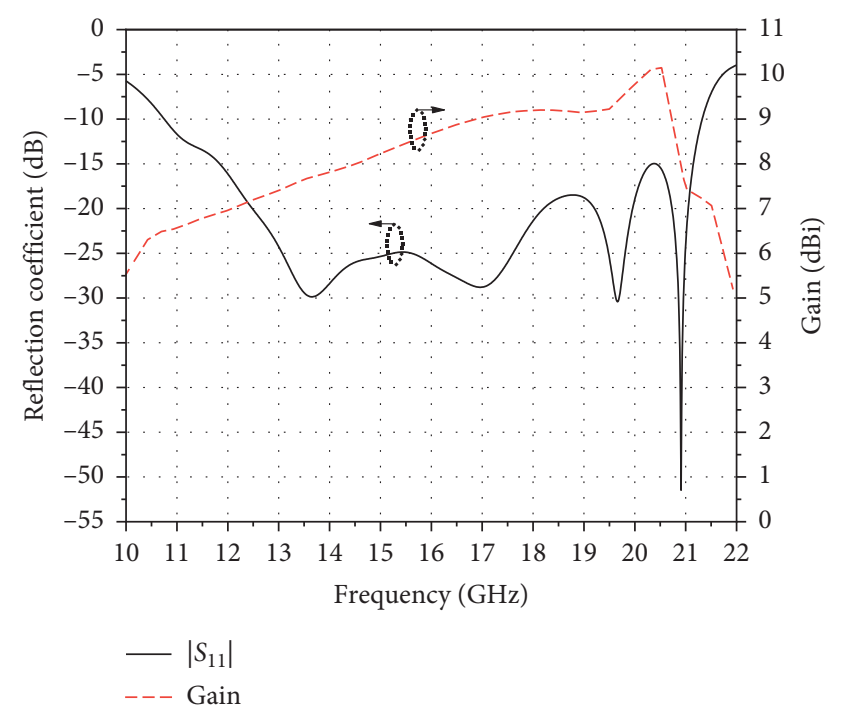

FIGURE 5: The simulated S-parameters and gain of the antenna element.

antenna element reaches $66 \%(10.7-21.3 \mathrm{GHz})$ for $|S 11|<-10 \mathrm{~dB}$, and the simulated maximum gain is $10.3 \mathrm{dBi}$ at $20.5 \mathrm{GHz}$. The simulated radiation patterns in both the E-plane and $\mathrm{H}$-plane at $12 \mathrm{GHz}, 16 \mathrm{GHz}$, and $20 \mathrm{GHz}$ are shown in Figures 6(a) and 6(b). Good unidirectional radiation characteristics and stable radiation pattern are obtained within the entire band. The cross-polarizations are less than $-30 \mathrm{~dB}$ in both planes. The comparison between the proposed antenna element and the previously reported antenna elements has been shown in Table 2. It shows that the proposed antenna element has a wider impedance bandwidth and higher gain than all reported antenna 


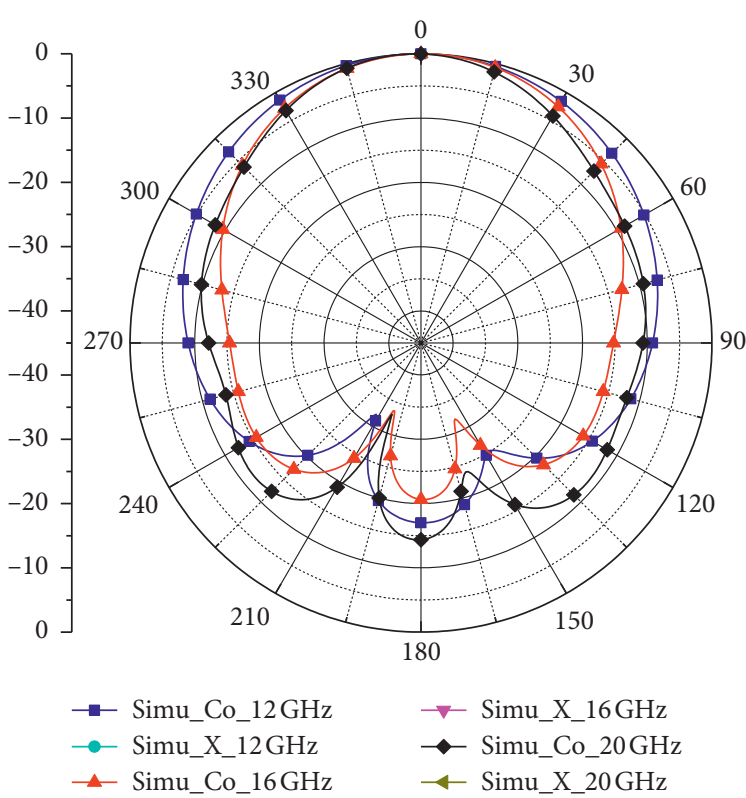

(a)

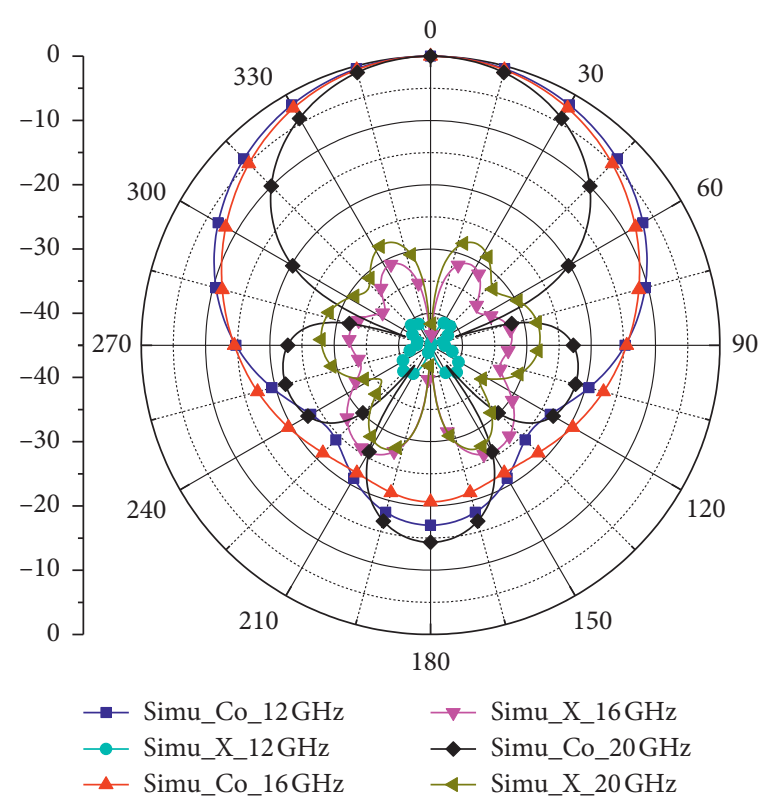

(b)

Figure 6: The simulated co- and cross-polarization radiation patterns of the proposed antenna element at $12 \mathrm{GHz}, 16 \mathrm{GHz}$, and $20 \mathrm{GHz}$. (a) E-plane (b) H-plane.

TABLE 2: Comparison among proposed and reported antenna elements.

\begin{tabular}{lccccc}
\hline Ref. & Type & Total size $\left(\lambda_{0}\right)$ & BW $(\%)$ & Max gain $(\mathrm{dBi})$ & X-pol. level $(\mathrm{dB})$ \\
\hline$[13]$ & Stripline-fed ME dipole antenna & $2.16 \times 2.16 \times 0.26$ & $45 \%$ & 8.9 & -20 \\
{$[26]$} & SIW-fed ME dipole antenna & $0.93 \times 0.87 \times 0.64$ & $19.6 \%$ & 8.7 & 8 \\
{$[27]$} & SIW-fed patch antenna & $1 \times 1 \times 0.46$ & $10.7 \%$ & -30 & -25 \\
{$[28]$} & SIW-fed slot antenna & $0.89 \times 0.87 \times 0.53$ & $21.8 \%$ & 9.3 & -30 \\
{$[29]$} & SIW-fed ME dipole antenna & $1 \times 1 \times 0.31$ & $28.8 \%$ & 9.4 & -13 \\
{$[33]$} & SIW-fed ME dipole antenna & $1.03 \times 1.03 \times 0.33$ & $38.7 \%$ & -20 \\
This work & SIW-fed ME dipole antenna & $0.88 \times 0.88 \times 0.26$ & $66.3 \%$ & 10.3 & -30 \\
\hline
\end{tabular}

elements. In particular, the size of the proposed antenna element is smaller than the reported antenna elements listed in Table 2. And the profile of the proposed antenna is lower than the reported antennas [26]- [29, 33]. Therefore, the structure of the proposed antenna is compact, and it is very beneficial for the design of the antenna array. All in all, the proposed antenna element has great advantages in terms of bandwidth, gain, and size. And all the characteristics of the proposed antenna element prove that it is suitable for wideband high-gain antenna array design.

\section{Antenna Array Design}

4.1. $2 \times 2$ Subarray. A compact, wideband, and high-gain cavity-backed aperture-coupled ME dipole antenna element has been proposed in the previous section. In order to obtain a higher gain, a $2 \times 2$ subarray is designed based on the proposed ME dipole antenna element, as depicted in Figure 7. The spacing between the antenna element is $16.5 \mathrm{~mm}$ in both $x$ - and $y$-directions. A corporate SIW feeding network is introduced to feed the $2 \times 2$ subarray, which is two-layer and consists of substrate 2 and substrate 3 , as shown in Figures 7(b) and 7(c). In the corporate SIW feeding network, a coupling slot is etched on the top surface of SIW in substrate 3 , which is used to couple the energy from substrate 3 to substrate 2. Four coupling slots are etched on the top surface of SIW in substrate 2, and the coupled energy can be divided into four parts to excite four antenna elements through four coupling slots. In order to better show the overall structure of the proposed antenna, an exploded view of the proposed $2 \times 2$ subarray is shown in Figure 8 . The optimized dimensions of the proposed $2 \times 2$ subarray are given in Table 3 .

The simulation model of the proposed feeding network of $2 \times 2$ subarray is shown in Figure 9. And the simulated results of the four-way power divider are shown in Figure 10. The impedance bandwidth of the power divider for $|S 11|<-10 \mathrm{~dB}$ is $35.4 \%$ over a 12.1 to $17.3 \mathrm{GHz}$ frequency range. In Figure 10(b), it can be seen that there is a slight difference in the magnitude between output ports $2-5$. The reason for the power imbalance is that an imbalance electric field distribution occurs in the slot-coupling feeding port. In Figure 10(c), it shows that the phases at output ports 2 and 3 and output ports 4 and 5 are reversed. In order to achieve the same phase excitation, four coupling slots are symmetrically etched on both sides of the feeding network. The simulated magnetic field distribution in substrate 2 at $15 \mathrm{GHz}$ is shown 


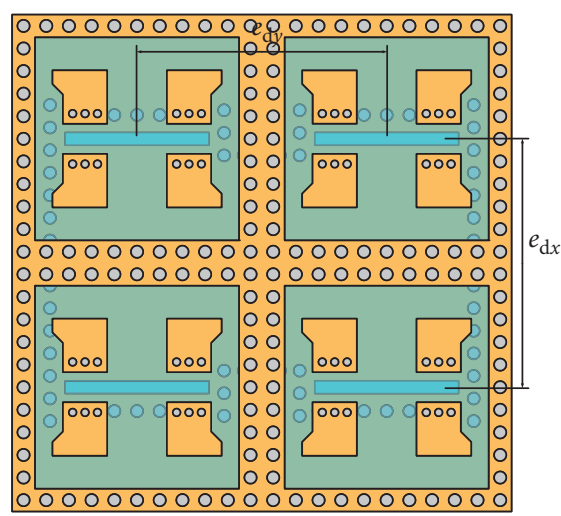

(a)

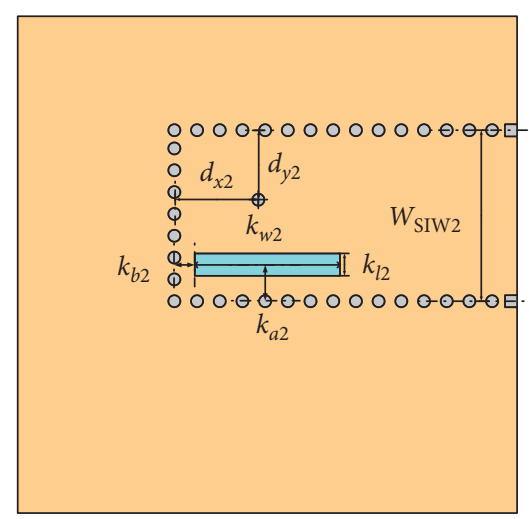

(c)

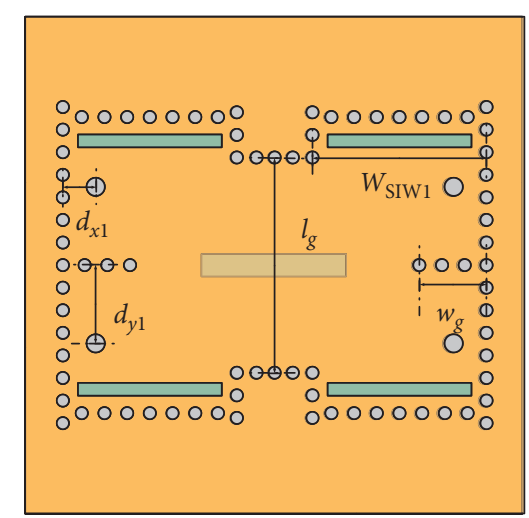

(b)

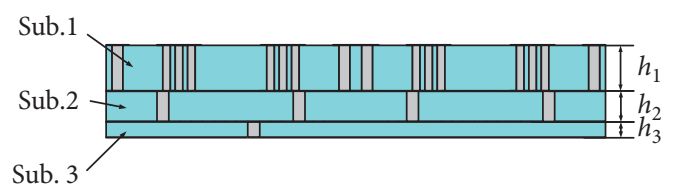

(d)

Figure 7: Configuration of the proposed $2 \times 2$ subarray. (a) Top view of substrate 1. (b) Top view of substrate 2. (c) Top view of substrate 3. (d) Left view.

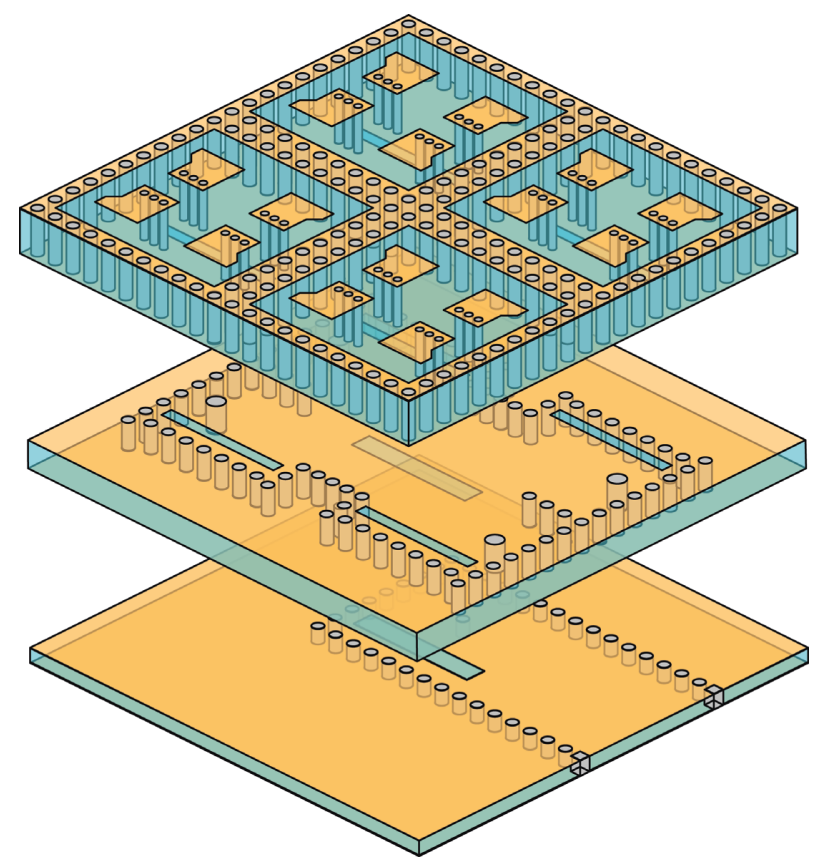

FIGURE 8: $3 \mathrm{D}$ exploded view of the proposed $2 \times 2$ subarray.

TABLE 3: Dimensions of $2 \times 2$ subarray (unit: $\mathrm{mm}$ ).

\begin{tabular}{lcccccccc}
\hline Para. & $d_{x 1}$ & $d_{y 1}$ & $l_{g}$ & $w_{g}$ & $W_{\text {siw1 }}$ & $d_{x 2}$ & $d_{y 2}$ & $k_{a 2}$ \\
\hline Values & 2.12 & 5.23 & 14.8 & 4.44 & 11.5 & 5.45 & 4.16 & 2.63 \\
Para. & $k_{b 2}$ & $k_{l 2}$ & $k_{w 2}$ & $W_{\text {siw2 }}$ & $h_{3}$ & $e_{\mathrm{d} x}$ & $e_{\mathrm{d} y}$ & \\
Values & 1.35 & 1.49 & 9.6 & 11.76 & 1 & 16.5 & 16.5 & \\
\hline
\end{tabular}




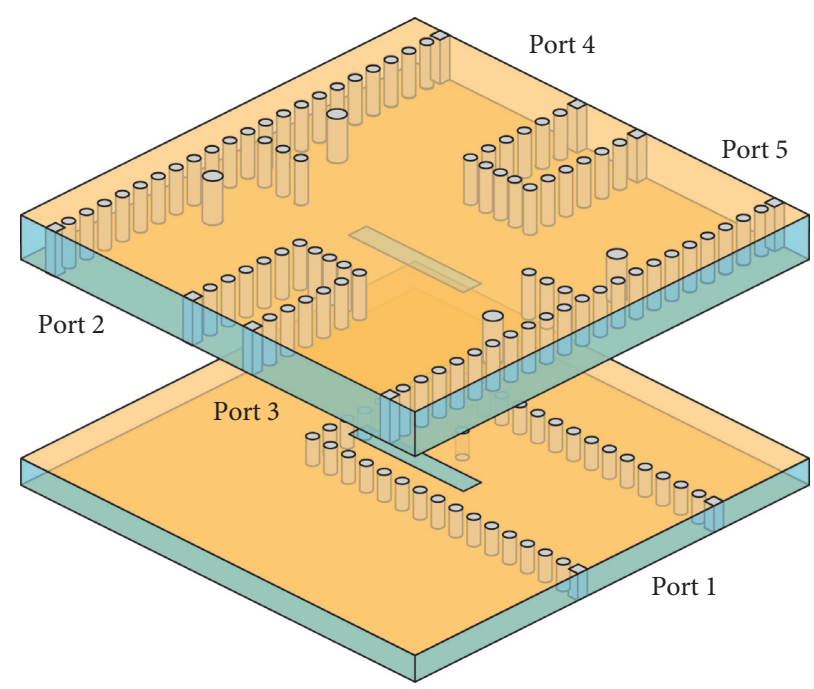

Figure 9: 3D exploded view of the feeding network of the $2 \times 2$ subarray.

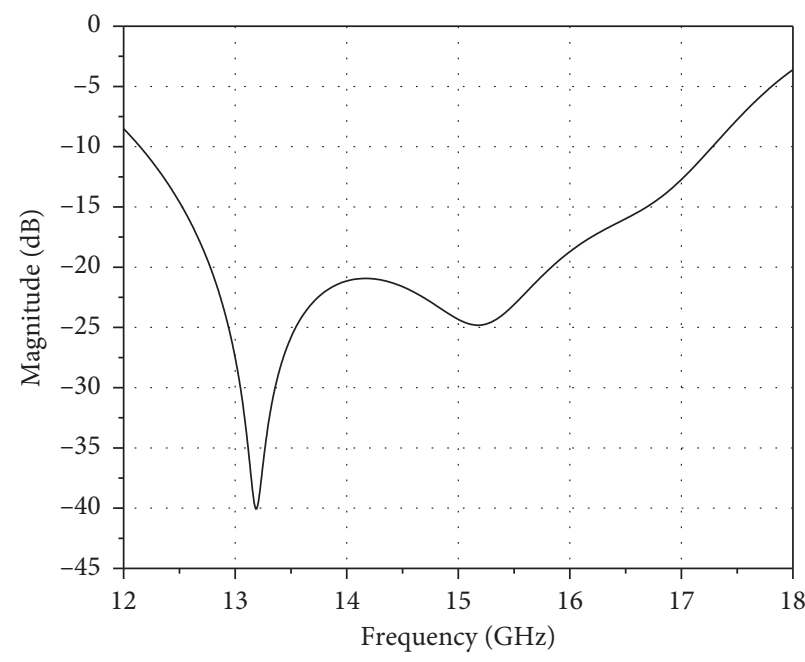

$-\left|S_{11}\right|$

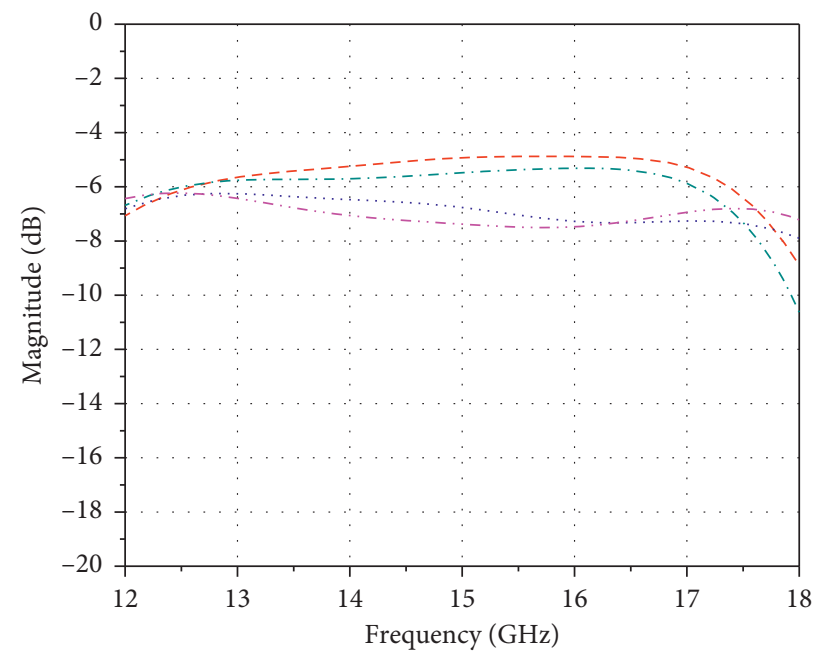

- - $\left|S_{21}\right|$

-..- $\left|S_{41}\right|$

$\left|S_{31}\right|$

(a)

(b)

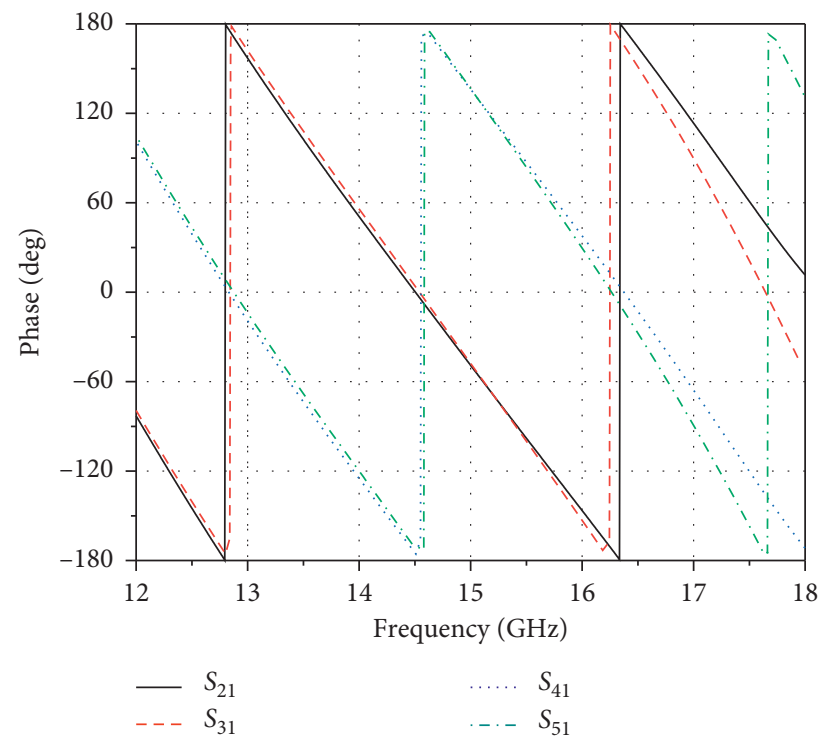

(c)

Figure 10: Simulated results of the two-layer feeding network of $2 \times 2$ subarray. (a) $S_{11}$. (b) S-parameters. (c) Phase. 
in Figure 11. It can be seen that the energy from substrate 3 is divided into four parts of the $\mathrm{TE}_{10}$ mode. Therefore, the mode supported by SIW is $\mathrm{TE}_{10}$ mode.

The full-wave simulated results of reflection coefficient and gain of the $2 \times 2$ subarray are shown in Figure 12. The simulated impedance bandwidth of the proposed $2 \times 2$ subarray for $|S 11|<-10 \mathrm{~dB}$ is $31.2 \%$ ranging from 12.7 to $17.4 \mathrm{GHz}$, and the maximum gain is $15.2 \mathrm{dBi}$. The simulated radiation patterns in both E-plane and $\mathrm{H}$-plane at $13 \mathrm{GHz}$, $15 \mathrm{GHz}$, and $17 \mathrm{GHz}$ are shown in Figure 13. It can be seen that the $2 \times 2$ subarray has good unidirectional radiation characteristics and low cross-polarization. The cross-polarization level is lower than $-40 \mathrm{~dB}$ in both planes. However, the radiation pattern of the subarray is slightly asymmetrical at high frequencies. The reason is that, within a wide impedance bandwidth of $35.4 \%$, the wavelength becomes shorter with the increasing of the frequency, and an imbalance electric field distribution occurs in the slot-coupling feeding port on the bottom layer. Therefore, the power distribution in the feeding network is unbalanced, which may affect the symmetry of the radiation pattern.

4.2. $4 \times 4$ Array. To satisfy the requirements of high gain in the application, based on the $2 \times 2$ subarray, a $4 \times 4 \mathrm{ME}$ dipole antenna array antenna with a two-layer full-corporate SIW feeding network is designed. Four $2 \times 2$ subarrays are simultaneously excited through a planar four-way $\mathrm{H}$-shaped power divider built in substrate 1 .

Figure 14 shows the configuration of the proposed wideband ME dipole antenna array. Figure 14(a) shows the top view of the radiation structure in substrate 3 ; it includes 16 radiating elements. The corporate SIW feeding network in substrate 2 of the proposed antenna array is shown in Figure 14(b). It consists of four identical 1-4 SIW power dividers, which are used to excite 16 radiating elements with equal amplitude and in phase, simultaneously. Figure 14(c) shows that a planar four-way $\mathrm{H}$-shaped feeding network is built in substrate 1. Four coupling slots on the top surface of SIW in substrate 1 are etched on the same side of the SIW $\mathrm{H}$-shaped power divider for the same phase excitation of the subarray. In order to further show the overall structure of the proposed array, an exploded view of the proposed $4 \times 4$ cavity-backed aperture-coupled ME dipole antenna array is shown in Figure 15. Moreover, a wideband grounded coplanar waveguide (GCPW) to SIW transition is designed for antenna measurement [22], as shown in Figure 14(c). The structure of SMA-to-SIW is shown in Figure 15. The simulated S-parameters of SMA-to-SIW are shown in Figure 16. It shows that the transmission structure has wide transmission bandwidth and low loss. The dimensions of the feeding structure are given in Table 4 .

Briefly, the steps of the design of the antenna can be summarized as follows:

(1) According to the operating frequency, select the width of the substrate integrated waveguide (SIW), and make the SIW-feedline propagate the main mode $\left(\mathrm{TE}_{10}\right.$ mode) within the working bandwidth.

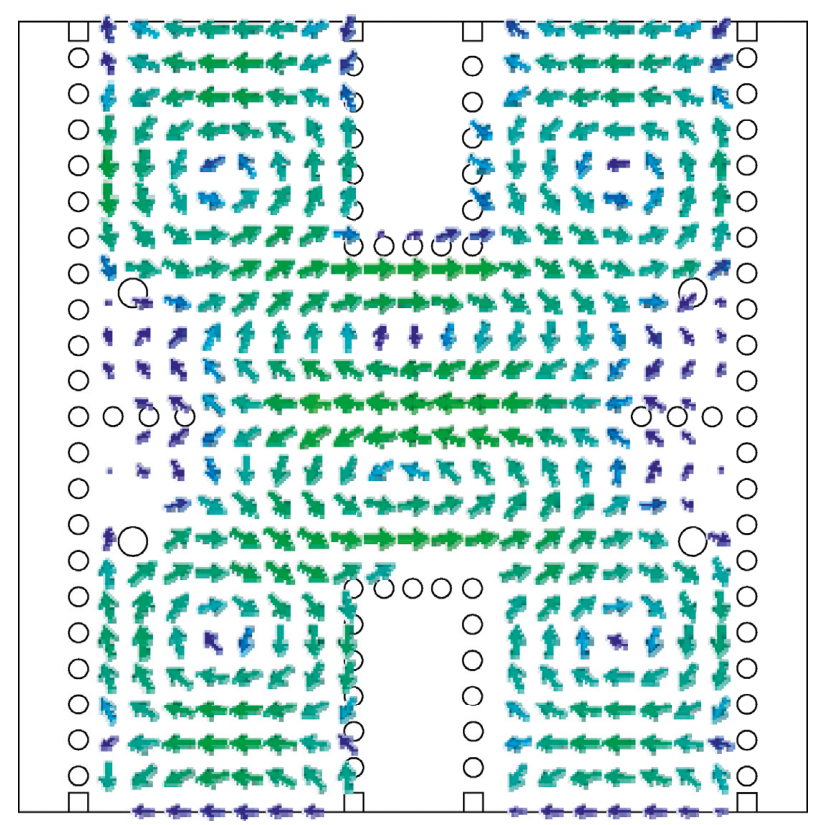

FIgURE 11: Simulated magnetic field distribution in the feeding network of $2 \times 2$ subarray at $15 \mathrm{GHz}$.

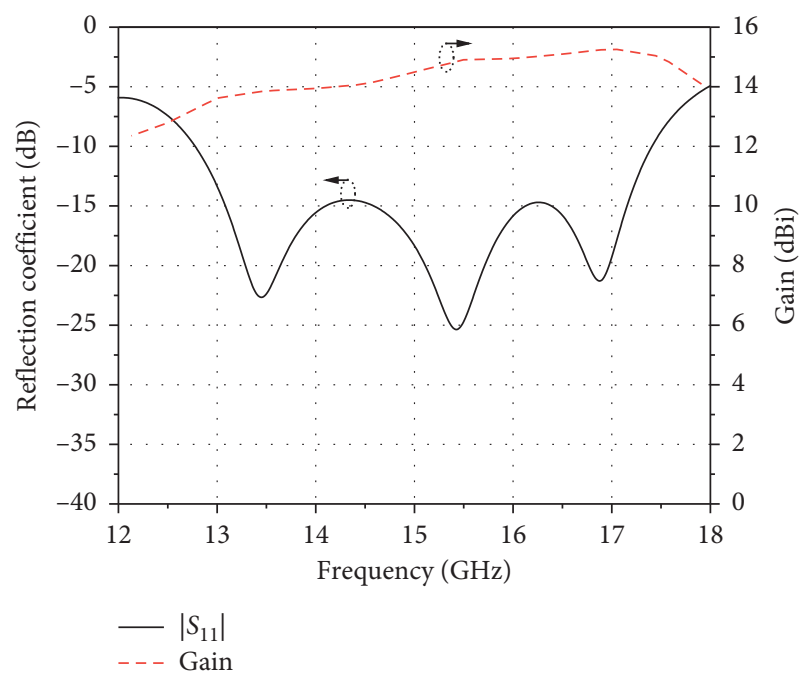

FIGURE 12: Simulated results of the proposed $2 \times 2$ subarray.

And design the size of the dipoles and cavity, and make the antenna element work in wide frequency bandwidth.

(2) Design 1-4 power dividers, and then by combining four antenna elements with the designed power divider, design a $2 \times 2$ subarray.

(3) Design another 4-way H-shaped SIW power divider, and expand the designed $2 \times 2$ subarray to a $4 \times 4$ array.

(4) Design a transition structure from SIW to grounded coplanar waveguide (GCPW) with wide impedance bandwidth and to connect an SMA connector. 


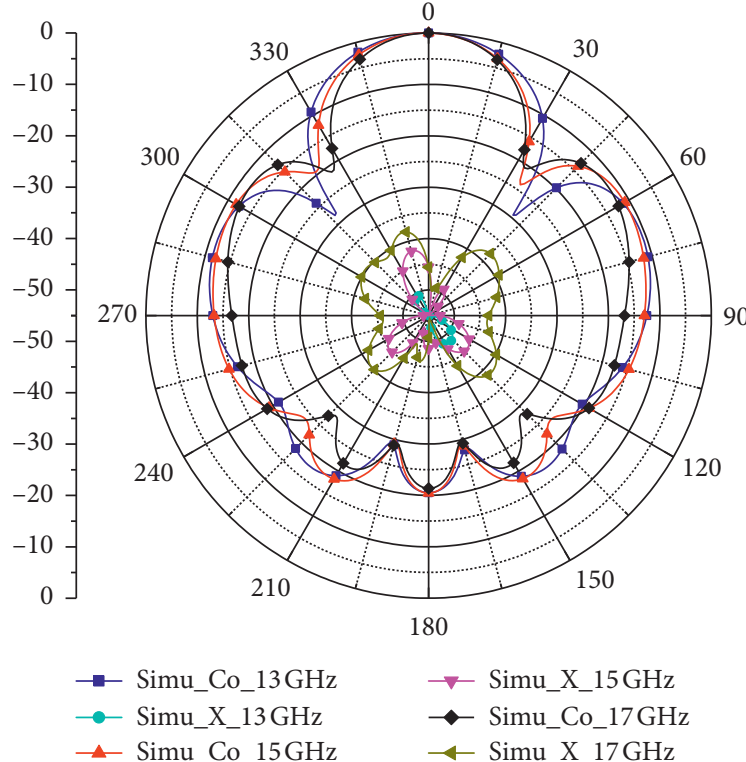

(a)

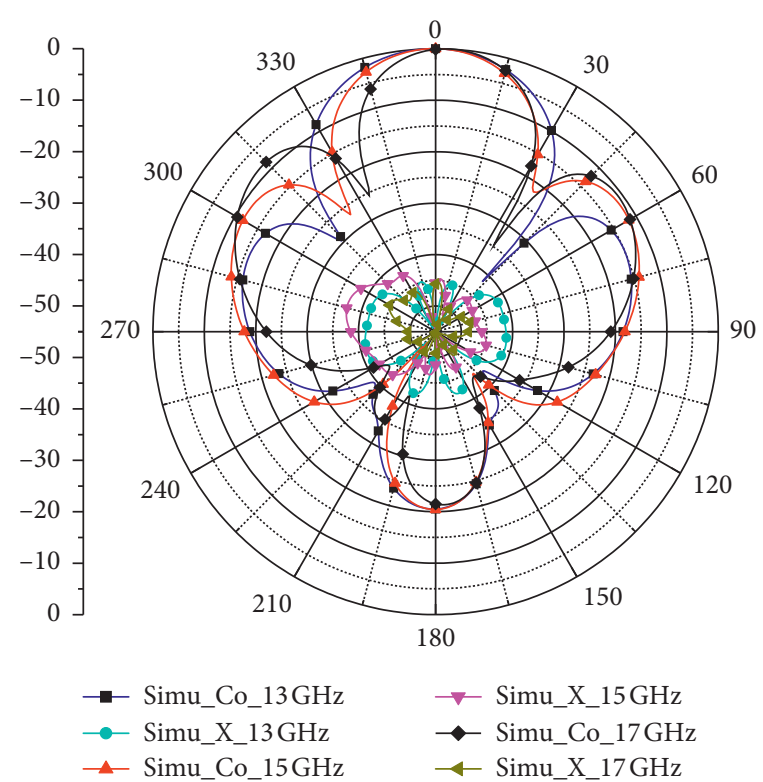

(b)

FIgURE 13: The simulated co- and cross-polarization radiation patterns of the proposed $2 \times 2$ subarray at $13 \mathrm{GHz}, 15 \mathrm{GHz}$, and $17 \mathrm{GHz}$ on (a) E-plane and (b) H-plane.

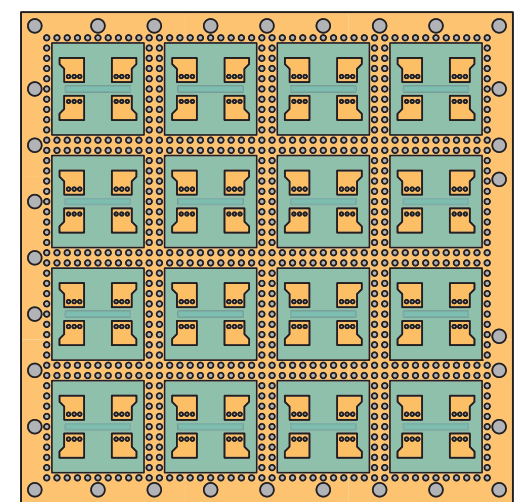

(a)

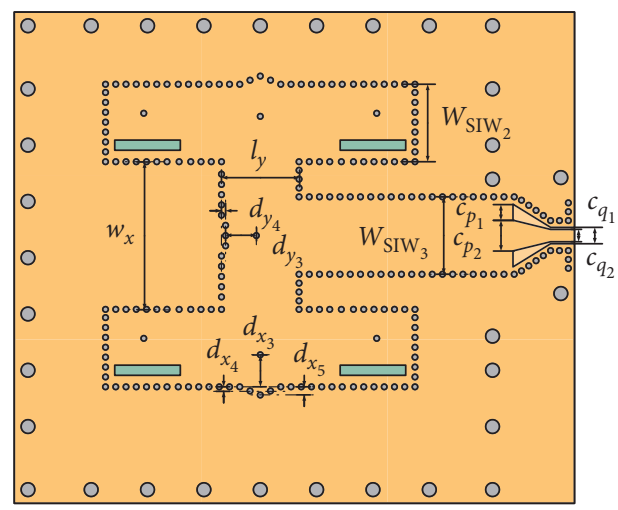

(c)

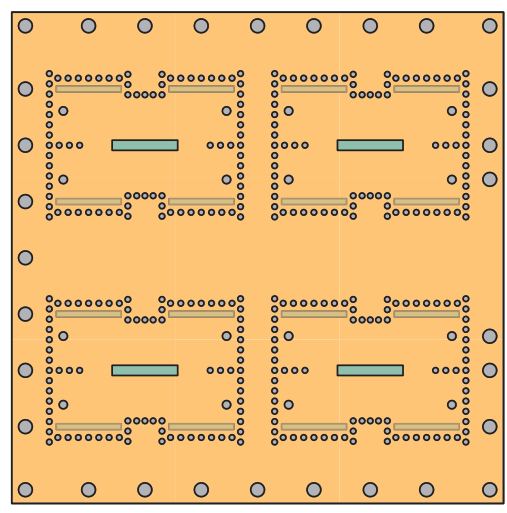

(b)

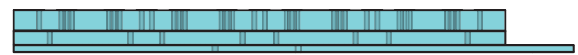

(d)

FIGURE 14: Configuration of the proposed $4 \times 4$ ME dipole antenna array with two-layer full-corporate SIW feeding network. (a) Top view of the radiation structure in substrate 3. (b) Top view of the corporate SIW feeding network in substrate 2. (c) Top view of the H-shaped feeding network in substrate 1. (d) Left view. 


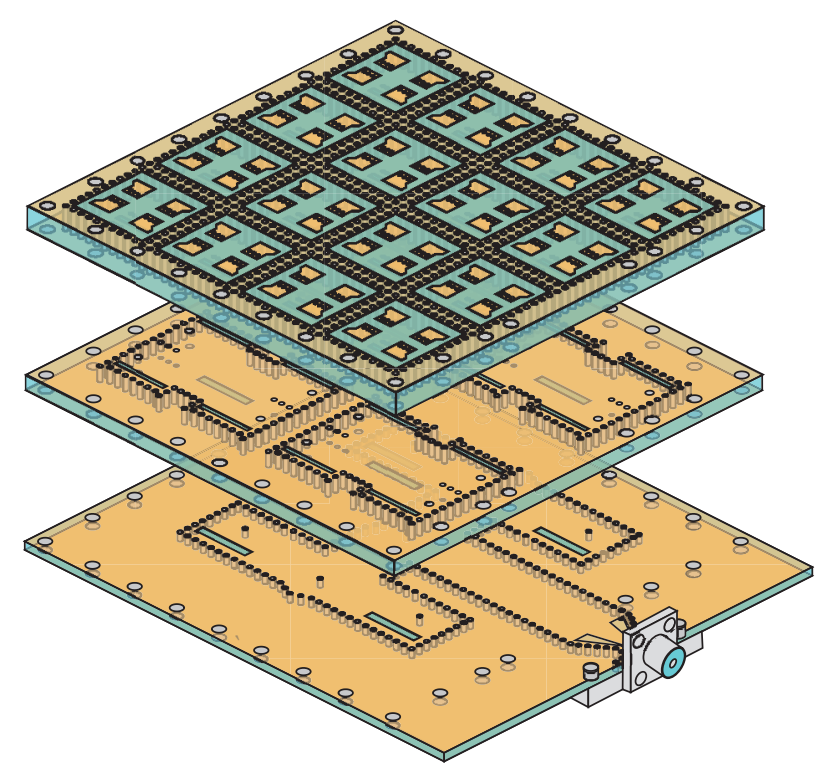

Figure 15: 3D exploded view of the proposed $4 \times 4 \mathrm{ME}$ dipole antenna array with two-layer full-corporate SIW feeding network.

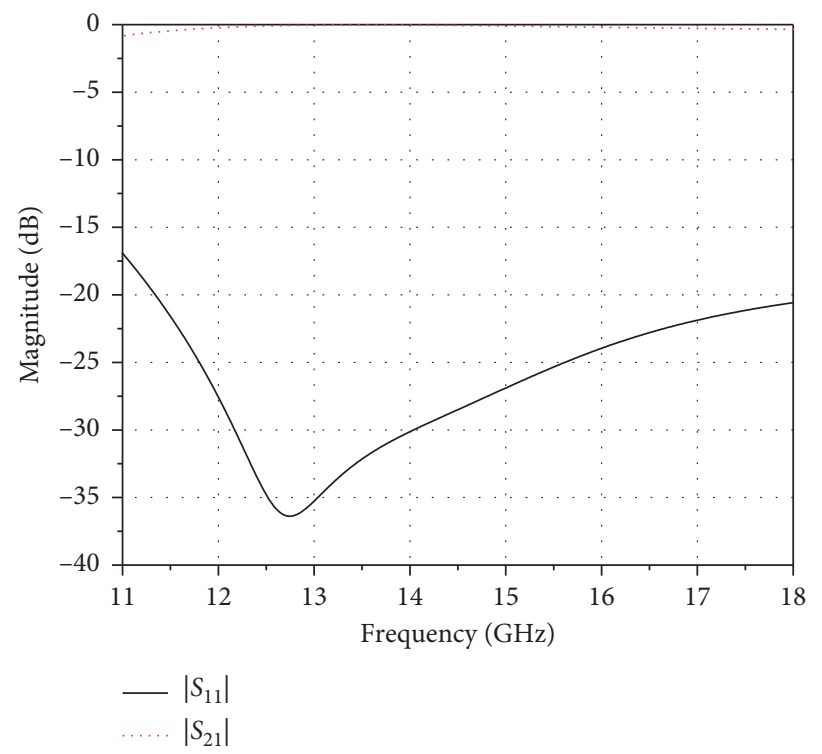

FIgURE 16: Simulated S-parameters of SMA-to-SIW.

TABLE 4: Dimensions of the feeding structure (unit: $\mathrm{mm}$ ).

\begin{tabular}{llllllll}
\hline Para. & $d_{x 3}$ & $d_{y 3}$ & $d_{y 4}$ & $d_{x 5}$ & $w_{x}$ & $l_{y}$ & $W_{\text {siw3 }}$ \\
\hline Values & 5.1 & 5.1 & 0.6 & 1.2 & 0.6 & 11.35 & 11.35 \\
Para. & $c_{p 2}$ & $c_{q 1}$ & $c_{q 2}$ & & & & \\
Values & 4.5 & 1.8 & 2.4 & & & & \\
\hline
\end{tabular}

Different parts of the antenna need to be designed and optimized to achieve good impedance matching and stable radiation patterns.

\section{Experimental Results}

To further validate the capability of the design, a prototype of the proposed $4 \times 4$ cavity-backed aperture-coupled $\mathrm{ME}$ dipole antenna array was fabricated and tested, as shown in Figure 17. The overall size of the fabricated antenna array is $72 \mathrm{~mm} \times 82 \mathrm{~mm} \times 6 \mathrm{~mm}$. The simulated and measured reflection coefficient of the proposed antenna array are illustrated in Figure 18(a). A good agreement between simulated and measured results is obtained. The simulated and measured fractional impedance bandwidths of the proposed antenna array are $29 \%$ from 12.9 to $17.3 \mathrm{GHz}$ and 


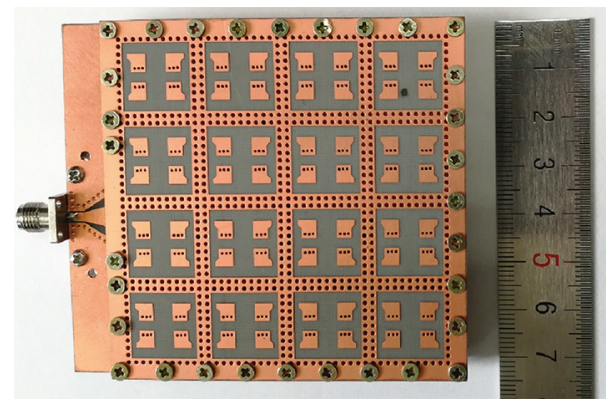

Figure 17: Photograph of the fabricated $4 \times 4$ ME dipole antenna array.

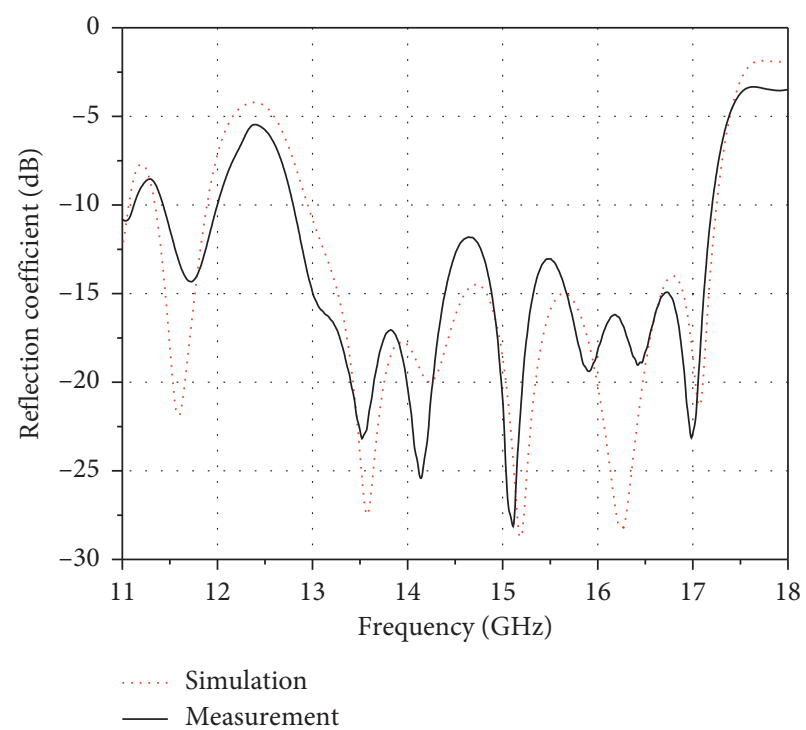

(a)

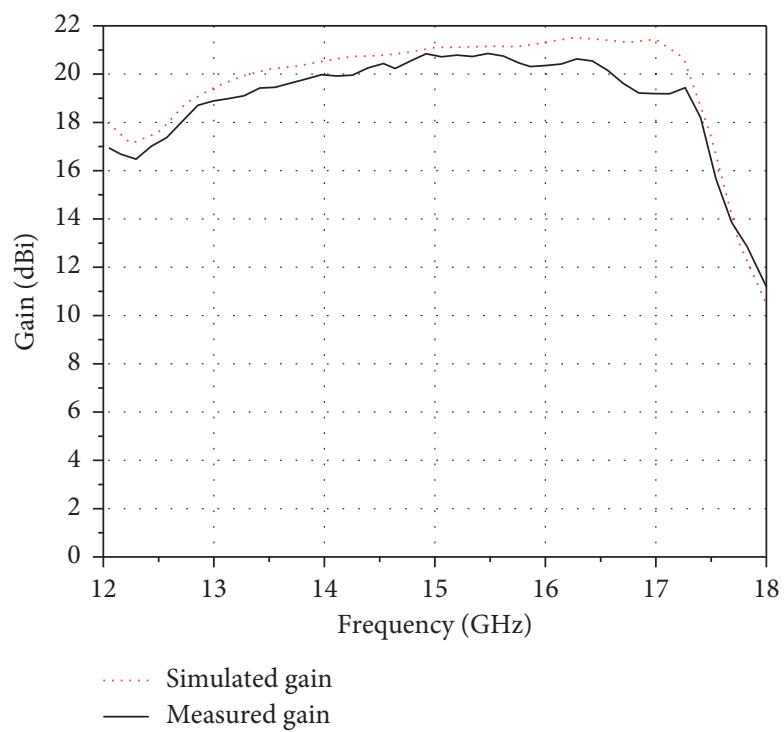

(b)

FIGURE 18: Simulated and measured S-parameters and gain of the antenna array. (a) Reflection coefficient. (b) Boresight gains.

$30 \%$ from 12.75 to $17.25 \mathrm{GHz}$ for $|S 11|<-10 \mathrm{~dB}$, respectively. The radiation performance of the proposed antenna array was measured by using far-field measurement system. The gain of the array was obtained by comparison with a standard horn. The simulated and measured gain results are depicted in Figure 18(b), and it shows that the measured gain range is $18.2-20.9 \mathrm{dBi}$. The simulated and measured gain results share similar trends, but the measured gain is about $1.0 \mathrm{~dB}$ lower than the simulated results at higher frequencies. The main reason for this difference is that fabrication error and material loss are larger at high frequencies. Moreover, in the process of measurement, the performance of the antenna array is more easily affected by the test environment at high frequencies. In addition, the simulated radiation efficiencies for $4 \times 4$ are above $90 \%$ within the impedance bandwidth. The measured radiation efficiency can be calculated by comparing the simulated directivity and the measured gain [26]. Then, the measured radiation efficiency of the $4 \times 4$ array is $91.9 \%$ at $14.92 \mathrm{GHz}$.

In the design of the proposed cavity-backed ME dipole array, for ease of installation, the outer edge of the proposed

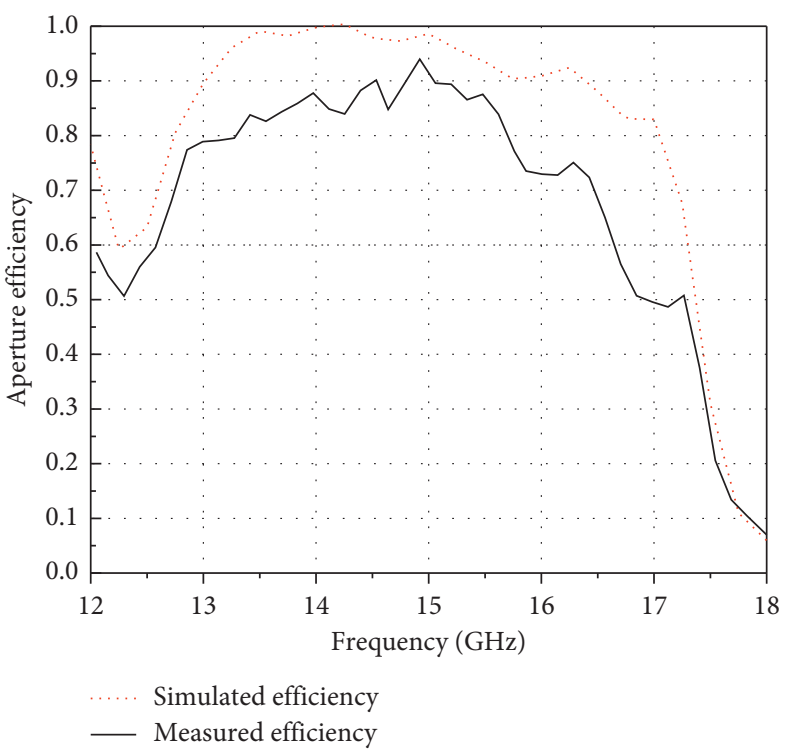

FIGURE 19: Simulated and measured aperture efficiency of the antenna array. 

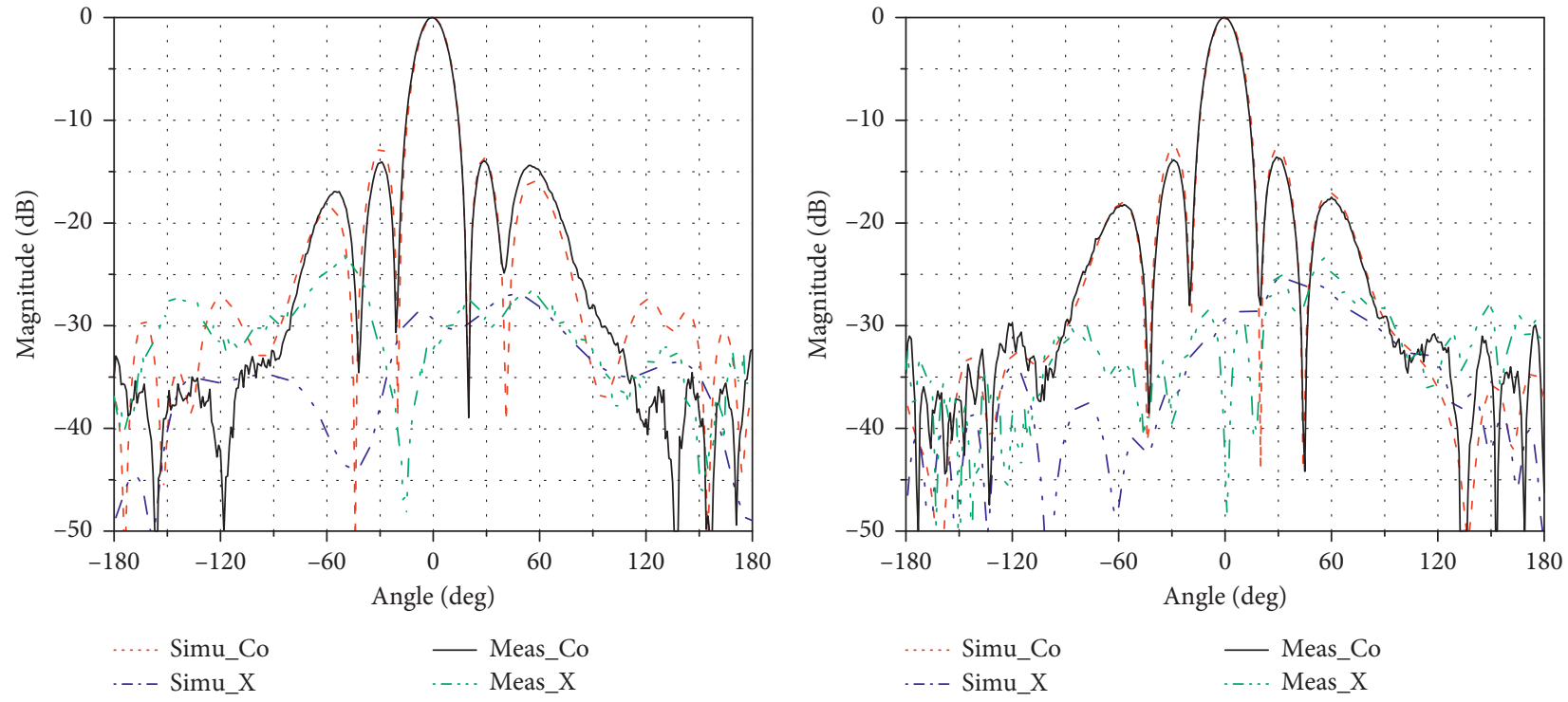

(a)
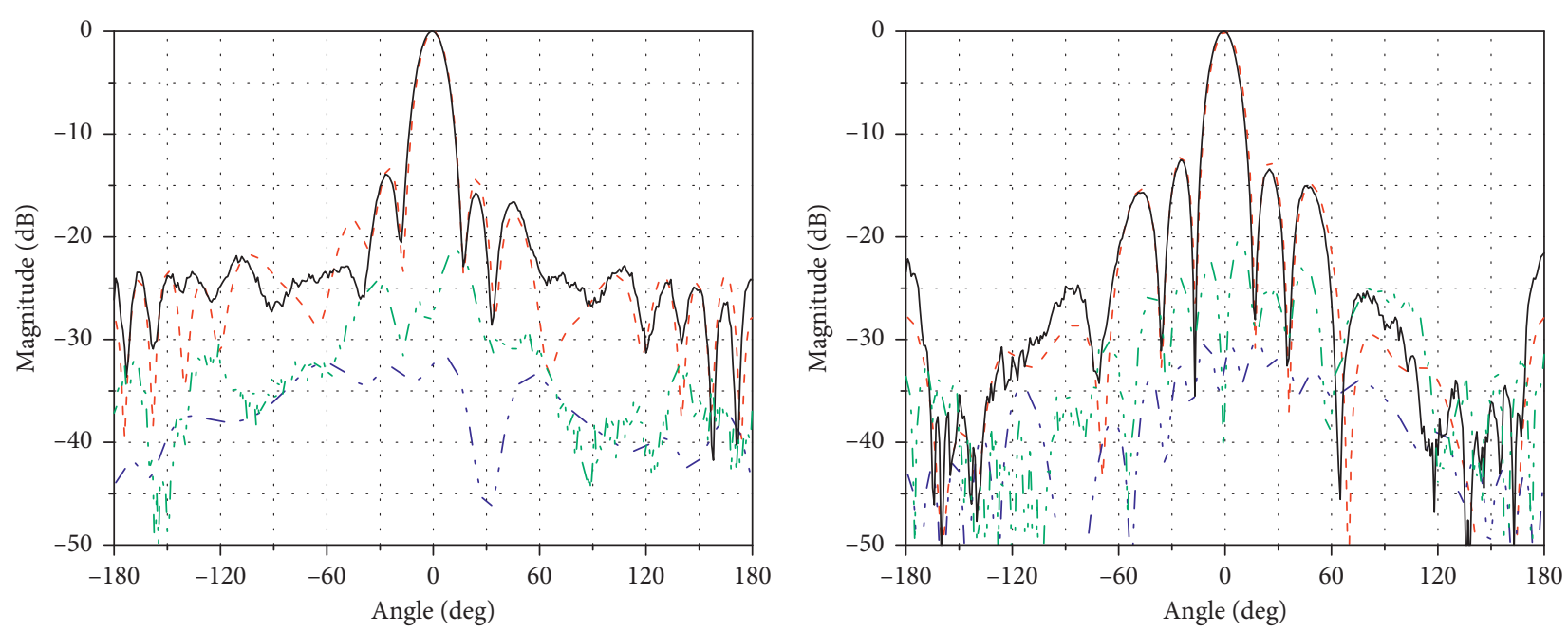

$\begin{array}{ll}\text {.... Simu_Co } & - \text { Meas_Co } \\ \text {..-S Simu_X } & \text {-. . Meas_X }\end{array}$

..... Simu_Co
.-.-Simu_X

- Meas_Co

(c)

(d)

FIgURe 20: Continued. 


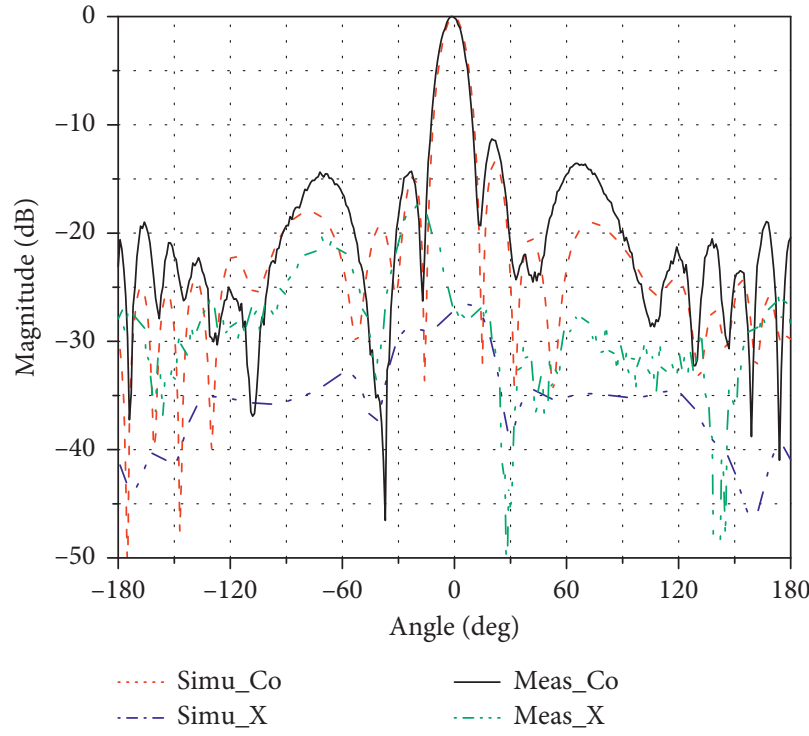

(e)

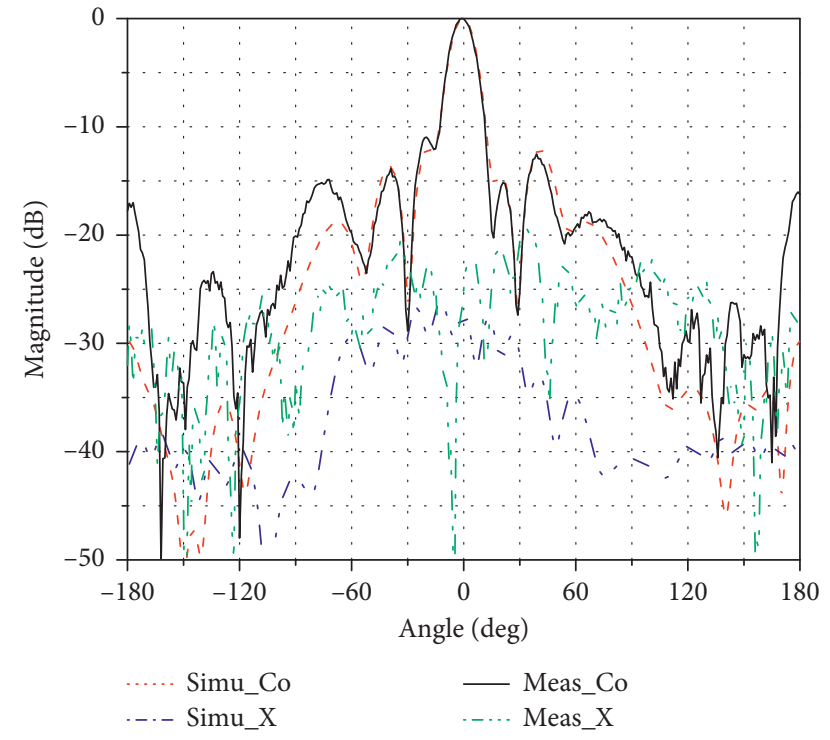

(f)

FIGURE 20: The simulated and measured co- and cross-polarization radiation patterns of the proposed antenna array at different frequencies. (a) E-plane at $13 \mathrm{GHz}$. (b) H-plane at $13 \mathrm{GHz}$. (c) E-plane at $15 \mathrm{GHz}$. (d) H-plane at $15 \mathrm{GHz}$ (e) E-plane at $17 \mathrm{GHz}$. (f) H-plane at $17 \mathrm{GHz}$.

TABLE 5: Comparison to other antenna elements/arrays.

\begin{tabular}{|c|c|c|c|c|c|c|c|}
\hline Ref. & Antenna type & Elements & Total size $\left(\lambda_{0}\right)$ & $\begin{array}{c}\text { Impedance } \\
\text { bandwidth } \\
(\%)\end{array}$ & $\begin{array}{c}\text { 3-dB gain } \\
\text { bandwidth } \\
(\%)\end{array}$ & $\begin{array}{l}\text { Max } \\
\text { gain } \\
(\mathrm{dBi})\end{array}$ & $\begin{array}{l}\text { Max aperture } \\
\text { efficiency }(\%)\end{array}$ \\
\hline [19] & Slot array fed by hollow waveguide & $16 \times 16$ & $15.4 \times 15.6 \times 0.6$ & 8.3 & 8.3 & 33 & 83.8 \\
\hline [20] & $\begin{array}{c}\text { Slot array fed by metallic ridge gap } \\
\text { waveguide }\end{array}$ & $16 \times 16$ & $16.2 \times 16.2 \times 2$ & 16 & 17.9 & 32.5 & 81.4 \\
\hline$[21]$ & $\begin{array}{l}\text { ME dipole array fed by printed ridge gap } \\
\text { waveguide }\end{array}$ & $4 \times 4$ & $3.5 \times 3.4 \times 0.28$ & 16.5 & 16.5 & 21.2 & 90 \\
\hline [26] & SIW-fed ME dipole array & $8 \times 8$ & $8.47 \times 10.96 \times 0.847$ & 16.3 & 16.3 & 26.7 & 86.1 \\
\hline [27] & SIW-fed cavity-backed patch & $16 \times 16$ & $15.6 \times 17.4 \times 0.85$ & 15.3 & 16.1 & 30.1 & 80.4 \\
\hline [28] & SIW-fed slot array & $4 \times 4$ & $8.82 \times 5.09 \times 0.8$ & 20.5 & 20.5 & 19.4 & 79.3 \\
\hline [29] & SIW-fed ME dipole array & $8 \times 8$ & $7.52 \times 8.36 \times 0.48$ & 18.2 & 18.2 & 26.1 & $\mathrm{~N} / \mathrm{A}$ \\
\hline [30] & SIW-fed slot array & $16 \times 16$ & $12 \times 12.6 \times 0.13$ & 19.2 & 15 & 29.1 & 42.8 \\
\hline [31] & SIW cavity-backed slot array & $8 \times 8$ & $10.56 \times 10.56 \times 0.51$ & 17.1 & 13.1 & 22.3 & 46 \\
\hline [32] & SIW cavity-backed slot array & $4 \times 4$ & $\mathrm{~N} / \mathrm{A}$ & 26.5 & 26.5 & 20 & $\mathrm{~N} / \mathrm{A}$ \\
\hline$[33]$ & SIW-fed ME dipole array & $4 \times 4$ & $4.3 \times 4.3 \times 0.51$ & 26.7 & 26.7 & 21.5 & 87.7 \\
\hline $\begin{array}{l}\text { This } \\
\text { work }\end{array}$ & SIW-fed ME dipole array & $4 \times 4$ & $3.58 \times 3.96 \times 0.3$ & 30 & 30 & 20.9 & 94 \\
\hline
\end{tabular}

antenna array is widened. However, its size of the outer edge has little effect on the radiation performance of the proposed antenna array due to the introduction of the semiclosed cavity-backed structure. Therefore, the effective physical aperture area of the proposed antenna array can be defined by the physical aperture area of the semiopening cavity, which has an area of $64.5 \mathrm{~mm} \times 64.5 \mathrm{~mm}$. The measured maximum gain is $20.9 \mathrm{dBi}$ at $14.92 \mathrm{GHz}$. Then, as the same in [26-33], the maximum aperture efficiency of the antenna array can be calculated by the following equation:

$$
\eta=\frac{G \lambda^{2}}{4 \pi S},
$$

where $G$ is the measured maximum gain and $S$ is the effective physical aperture of the proposed antenna array, and the definition of effective physical aperture is the same as that in [26-33]. The maximum aperture efficiency of the antenna array can be calculated as $94 \%$ at $14.92 \mathrm{GHz}$. The simulated and measured aperture efficiency of the antenna array within the entire band is shown in Figure 19.

The simulated and measured normalized radiation patterns in both E-plane and $\mathrm{H}$-plane at $13 \mathrm{GHz}, 15 \mathrm{GHz}$, and $17 \mathrm{GHz}$ are described in Figure 20. The measured results are consistent with the simulation results. Stable unidirectional radiation patterns can be observed within the operating frequency band. The measured cross-polarization level 
is less than $-20 \mathrm{~dB}$ at boresight. However, due to the impact of the test environment and fabrication accuracy, there is a deviation between the measured and simulated results about the side lobes and the cross-polarization levels. What is more, due to the small size of the antenna array, the influence of the feeding cable setting near the antenna in the measurement cannot be ignored. In general, good radiation performance is achieved by combining broadband high-gain radiating elements with low-loss full-corporate SIW feeding networks. Therefore, the wideband high-efficiency antenna array can satisfy the application requirements well and has great potential in future antenna applications.

Table 5 shows the comparison between the proposed antenna and the previously reported antennas. Observations of Table 5 show that the proposed antenna array has a wider impedance bandwidth and higher gain than the reported antennas [19-21, 26-33]. Moreover, the aperture efficiency of the proposed antenna array is also higher than all antennas proposed earlier in [19-21, 26-33]. Although the bandwidth of the SIW cavity-backed slot array in [32] is wide, and its radiation elements are composed of multilayer structures with a high profile and large size. Moreover, the structure is complicated and the cost is higher. Therefore, compared to the antennas referred above, the proposed antenna has a more compact structure, wider impedance bandwidth, and higher efficiency and gain.

\section{Conclusion}

In this paper, a compact, wideband, and high-efficiency SIW feeding cavity-backed aperture-coupled magneto-electric dipole antenna array has been presented and investigated at $\mathrm{Ku}$-band. A SIW cavity-backed is introduced to increase the gain and improve unidirectional radiation characteristics. A modified bowtie magneto-electric dipole is used to improve antenna impedance bandwidth. The high-gain radiation elements combined with low-loss full-corporate substrate integrated waveguide feeding networks are used to design antenna array for high efficiency. A $4 \times 4$ array prototype is designed and measured, which verifies the design method proposed in this paper and the characteristics of wideband and high efficiency. All in all, the proposed antenna array is a valuable candidate for modern wideband and high-gain antenna application.

\section{Data Availability}

The data used to support the findings of this study are available from the corresponding author upon request.

\section{Conflicts of Interest}

The authors declare that there are no conflicts of interest regarding the publication of this paper.

\section{Acknowledgments}

The article processing fee is supported by the National University of Defense Technology.

\section{References}

[1] G. Sun, G. Gao, T. Liu, Y. Liu, and H. Yang, "Design of wideband slot antenna array with stereoscopic differentially fed structures," International Journal of Antennas and Propagation, vol. 2019, Article ID 9285476, 14 pages, 2019.

[2] K. L. Wong, Compact and Broadband Microstrip Antennas, Wiley, Hoboken, NJ, USA, 2002.

[3] S. X. Ta, K. E. Kedze, D. N. Chien, and I. Park, "Bandwidthenhanced low-profile antenna with parasitic patches," International Journal of Antennas and Propagation, vol. 2017, no. 5, pp. 1-11, 2017.

[4] S.-H. Wi, Y.-S. Lee, and J.-G. Yook, "Wideband microstrip patch antenna with U-shaped parasitic elements," IEEE Transactions on Antennas and Propagation, vol. 55, no. 4, pp. 1196-1199, 2007.

[5] Y. Shi, J. Liu, and Y. Long, "Wideband triple-and quad-resonance substrate integrated waveguide cavity-backed slot antennas with shorting vias," IEEE Transactions on Antennas and Propagation, vol. 65, no. 11, pp. 5768-5775, 2017.

[6] K. M. Luk and H. Wong, "A new wideband unidirectional antenna element," International Journal of Microwave and Optical Technology, vol. 1, no. 1, pp. 35-44, 2006.

[7] L. Chang, J.-Q. Zhang, L.-L. Chen, and B.-M. Li, "Bandwidthenhanced cavity-backed magneto-electric dipole antenna," IEEE Access, vol. 6, pp. 62482-62489, 2018.

[8] C. Shuai and G. Wang, "Substrate-integrated low-profile unidirectional antenna," IET Microwaves, Antennas \& Propagation, vol. 12, no. 2, pp. 185-189, 2018.

[9] J. Zeng and K.-M. Luk, "A simple wideband magnetoelectric dipole antenna with a defected ground structure," IEEE Antennas and Wireless Propagation Letters, vol. 17, no. 8, pp. 1497-1500, 2018.

[10] H. W. Lai, K. K. So, H. Wong, C. H. Chan, and K. M. Luk, "Magnetoelectric dipole antennas with dual open-ended slot excitation," IEEE Transactions on Antennas and Propagation, vol. 64, no. 8, pp. 3338-3346, 2016.

[11] Y. Li and K.-M. Luk, "60-GHz dual-polarized two-dimensional switch-beam wideband antenna array of aperturecoupled magneto-electric dipoles," IEEE Transactions on Antennas and Propagation, vol. 64, no. 2, pp. 554-563, 2016.

[12] M. Li and K.-M. Luk, "Wideband magneto-electric dipole antenna for 60-GHz millimeter-wave communications," IEEE Transactions on Antennas and Propagation, vol. 63, no. 7, pp. 3276-3279, 2015.

[13] X. Cui, F. Yang, M. Gao, and Z. Liang, "Wideband microstrip magnetoelectric dipole antenna with stripline aperture-coupled excitation," IET Microwaves, Antennas \& Propagation, vol. 12, no. 9, pp. 1575-1581, 2018.

[14] Y. Li and K.-M. Luk, "A multibeam end-fire magnetoelectric dipole antenna array for millimeter-wave applications," IEEE Transactions on Antennas and Propagation, vol. 64, no. 7, pp. 2894-2904, 2016.

[15] W. Yang, K. Ma, K. S. Yeo, and W. M. Lim, "A compact highperformance patch antenna array for $60-\mathrm{GHz}$ applications," IEEE Antennas and Wireless Propagation Letters, vol. 15, pp. 313-316, 2016.

[16] X. F. Zhao, H. Z. Liu, L. Yi, S. G. Zhou, and C. Y. D. Sim, “A low VSWR and high efficiency waveguide feed antenna array," International Journal of Antennas and Propagation, vol. 2018, Article ID 7867091, 7 pages, 2018.

[17] G.-L. Huang, S.-G. Zhou, T.-H. Chio, and T.-S. Yeo, "Fabrication of a high-efficiency waveguide antenna array via 
direct metal laser sintering," IEEE Antennas and Wireless Propagation Letters, vol. 15, pp. 622-625, 2016.

[18] S.-G. Zhou, G.-L. Huang, T.-H. Chio, J.-J. Yang, and G. Wei, "Design of a wideband dual-polarization fullcorporate waveguide feed antenna array," IEEE Transactions on Antennas and Propagation, vol. 63, no. 11, pp. 4775-4782, 2015.

[19] Y. Miura, J. Hirokawa, M. Ando, Y. Shibuya, and G. Yoshida, "Double-layer full-corporate-feed hollow-waveguide slot array antenna in the $60-\mathrm{GHz}$ band," IEEE Transactions on Antennas and Propagation, vol. 59, no. 8, pp. 2844-2851, 2011.

[20] D. Zarifi, A. Farahbakhsh, A. U. Zaman, and P.-S. Kildal, "Design and fabrication of a high-gain $60-\mathrm{GHz}$ corrugated slot antenna array with ridge gap waveguide distribution layer," IEEE Transactions on Antennas and Propagation, vol. 64, no. 7, pp. 2905-2913, 2016.

[21] M. S. Sorkherizi, A. Dadgarpour, and A. A. Kishk, "Planar high-efficiency antenna array using new printed ridge gap waveguide technology," IEEE Transactions on Antennas and Propagation, vol. 65, no. 7, pp. 3772-3776, 2017.

[22] W.-W. Yang, W.-J. Sun, H. Tang, and J.-X. Chen, "Design of a circularly polarized dielectric resonator antenna with wide bandwidth and low axial ratio values," IEEE Transactions on Antennas and Propagation, vol. 67, no. 3, pp. 1963-1968, 2019.

[23] X. P. Chen, K. Wu, L. Han, and F. He, "Low-cost high gain planar antenna array for $60-\mathrm{GHz}$ band applications," IEEE Transactions on Antennas and Propagation, vol. 58, no. 6, pp. 2126-2129, 2010.

[24] H. Yang, G. Montisci, Z. Jin, Y. Liu, X. He, and G. Mazzarella, "Improved design of low sidelobe substrate integrated waveguide longitudinal slot array," IEEE Antennas and Wireless Propagation Letters, vol. 14, pp. 237-240, 2015.

[25] Y. Liu, H. Yang, Z. Jin, and J. Zhu, “An improvement approach for wide-angle impedance matching using ELC metasurface slabs for SIW slot array antennas," International Journal of Antennas and Propagation, vol. 2018, Article ID 3164147, 8 pages, 2018.

[26] X. Li, J. Xiao, Z. Qi, and H. Zhu, "Broadband and high-gain SIW-fed antenna array for $5 \mathrm{G}$ applications," IEEE Access, vol. 6, pp. 56282-56289, 2018.

[27] Y. Li and K.-M. Luk, " $60-\mathrm{GHz}$ substrate integrated waveguide fed cavity-backed aperture-coupled microstrip patch antenna arrays," IEEE Transactions on Antennas and Propagation, vol. 63, no. 3, pp. 1075-1085, 2015.

[28] J. Xiao, Z. Qi, X. Li, and H. Zhu, "Broadband and high-gain SIW-fed slot array for millimeter-wave applications," IEEE Transactions on Antennas and Propagation, vol. 67, no. 5, pp. 3484-3489, 2019.

[29] Y. Li and K.-M. Luk, "A 60-GHz wideband circularly polarized aperture-coupled magneto-electric dipole antenna array," IEEE Transactions on Antennas and Propagation, vol. 64, no. 4, pp. 1325-1333, 2016.

[30] D.-F. Guan, C. Ding, Z.-P. Qian, Y.-S. Zhang, W.-Q. Cao, and E. Dutkiewicz, "An SIW-based large-scale corporate-feed array antenna," IEEE Transactions on Antennas and Propagation, vol. 63, no. 7, pp. 2969-2976, 2015.

[31] Z. Chen, H. Liu, J. Yu, and X. Chen, "High gain, broadband and dual-polarized substrate integrated waveguide cavitybacked slot antenna array for $60 \mathrm{GHz}$ band," IEEE Access, vol. 6, pp. 31012-31022, 2018.

[32] Y. Cai, Y. Zhang, Z. Qian, and J. Liu, "A 16-element corporate-feed multilayer SIW cavity-backed slot antenna array," IET Microwaves, Antennas \& Propagation, vol. 11, no. 12, pp. 1796-1802, 2017.
[33] Q. Zhu, K. B. Ng, C. H. Chan, and K.-M. Luk, "Substrateintegrated-waveguide-fed array antenna covering $57-71 \mathrm{GHz}$ band for 5G applications," IEEE Transactions on Antennas and Propagation, vol. 65, no. 12, pp. 6298-6306, 2017. 


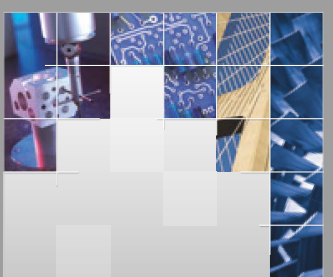

\section{Enfincering}
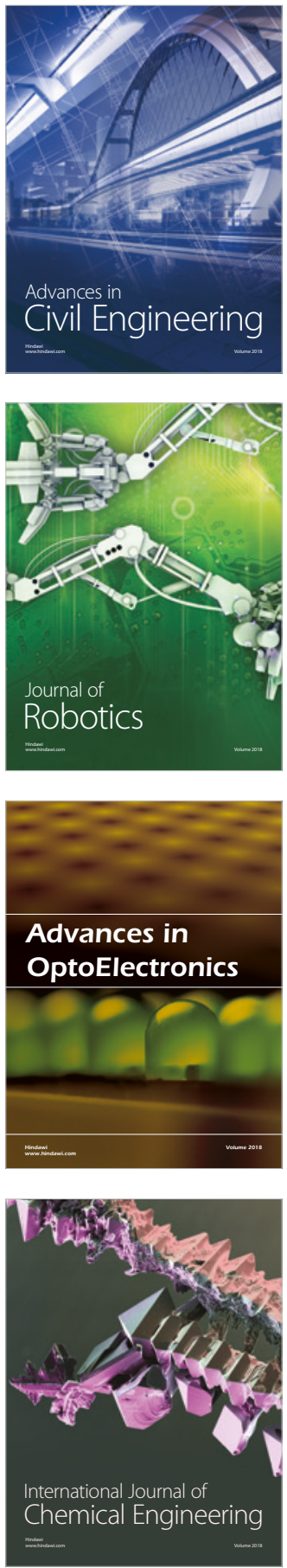

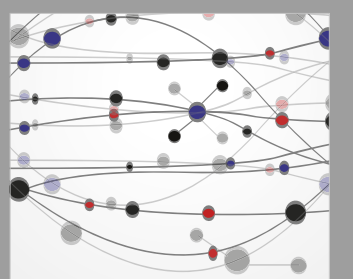

\section{Rotating \\ Machinery}

The Scientific World Journal

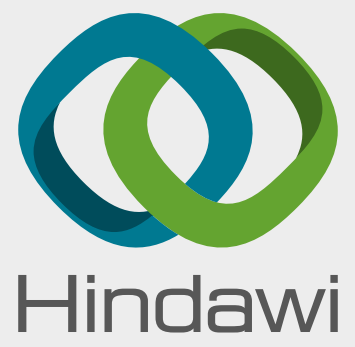

Submit your manuscripts at

www.hindawi.com
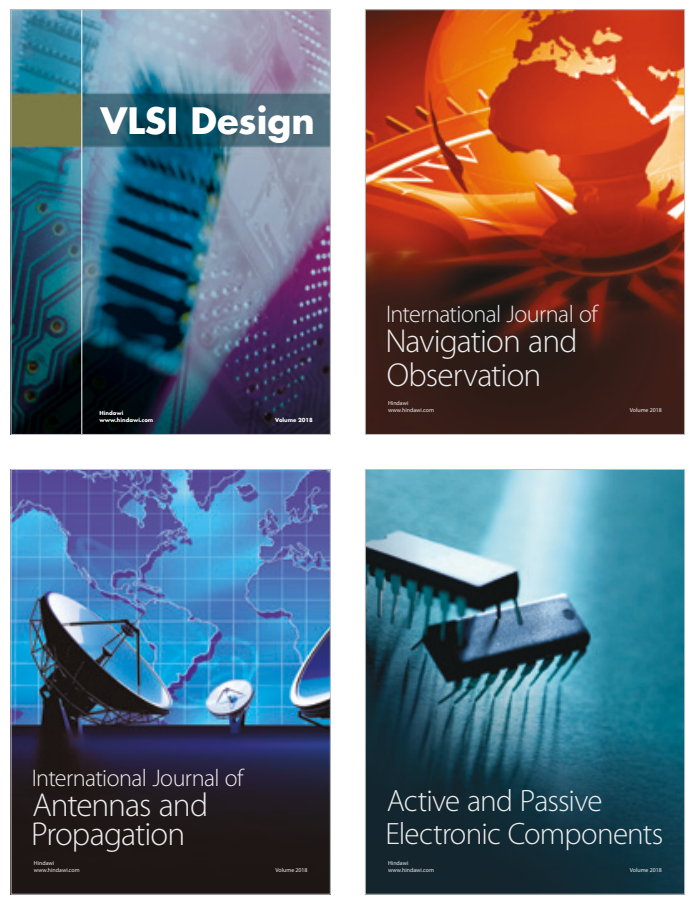
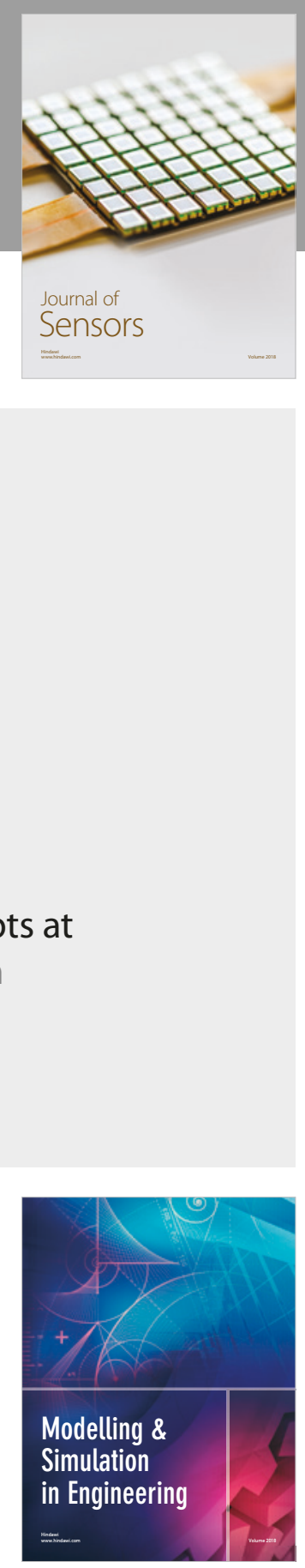

\section{Advances \\ Multimedia}
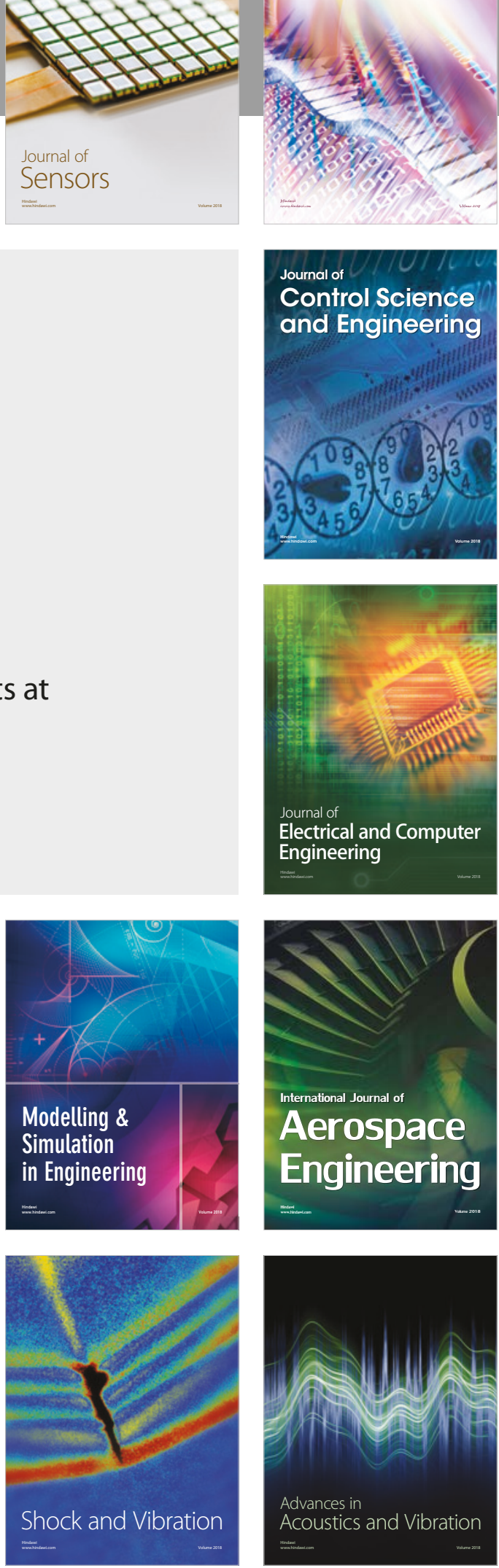